\title{
Inhibitors of class I HDACs and of FLT3 combine synergistically against leukemia cells with mutant FLT3
}

\author{
Vanessa Wachholz ${ }^{1}$ Al-Hassan M. Mustafa ${ }^{1,2}$ (D) Yanira Zeyn ${ }^{1} \cdot$ Sven J. Henninger ${ }^{1} \cdot$ Mandy Beyer $^{1}$. \\ Melanie Dzulko ${ }^{1}$. Andrea Piée-Staffa ${ }^{1}$. Christina Brachetti ${ }^{1}$. Patricia S. Haehnel ${ }^{3,4}$. Andreas Sellmer ${ }^{5}$.

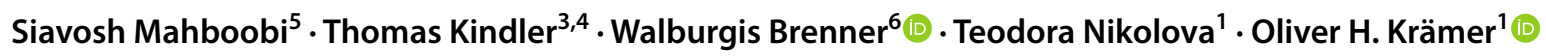

Received: 21 June 2021 / Accepted: 29 September 2021 / Published online: 19 October 2021

(c) The Author(s) 2021

\begin{abstract}
Acute myeloid leukemia (AML) with mutations in the FMS-like tyrosine kinase (FLT3) is a clinically unresolved problem. AML cells frequently have a dysregulated expression and activity of epigenetic modulators of the histone deacetylase (HDAC) family. Therefore, we tested whether a combined inhibition of mutant FLT3 and class I HDACs is effective against AML cells. Low nanomolar doses of the FLT3 inhibitor (FLT3i) AC220 and an inhibition of class I HDACs with nanomolar concentrations of FK228 or micromolar doses of the HDAC3 specific agent RGFP966 synergistically induce apoptosis of AML cells that carry hyperactive FLT3 with an internal tandem duplication (FLT3-ITD). This does not occur in leukemic cells with wild-type FLT3 and without FLT3, suggesting a preferential toxicity of this combination against cells with mutant FLT3. Moreover, nanomolar doses of the new FLT3i marbotinib combine favorably with FK228 against leukemic cells with FLT3-ITD. The combinatorial treatments potentiated their suppressive effects on the tyrosine phosphorylation and stability of FLT3-ITD and its downstream signaling to the kinases ERK1/ERK2 and the inducible transcription factor STAT5. The beneficial pro-apoptotic effects of FLT3i and HDACi against leukemic cells with mutant FLT3 are associated with dose- and drug-dependent alterations of cell cycle distribution and DNA damage. This is linked to a modulation of the tumor-suppressive transcription factor p53 and its target cyclin-dependent kinase inhibitor p21. While HDACi induce p21, AC220 suppresses the expression of p53 and p21. Furthermore, we show that both FLT3-ITD and class I HDAC activity promote the expression of the checkpoint kinases CHK1 and WEE1, thymidylate synthase, and the DNA repair protein RAD51 in leukemic cells. A genetic depletion of HDAC3 attenuates the expression of such proteins. Thus, class I HDACs and hyperactive FLT3 appear to be valid targets in AML cells with mutant FLT3.
\end{abstract}

Keywords AML $\cdot$ Drug interaction $\cdot$ FLT3-ITD $\cdot$ HDAC $\cdot$ HDACi $\cdot$ TKi

\section{Introduction}

The membrane-bound FMS-like tyrosine kinase-3 (FLT3) is activated by the FLT3 ligand and contributes to the development of hematopoietic cells. FLT3 is encoded on chromosome 13q12.2 and consists of five extracellular, immunoglobulin-like domains, a transmembrane domain, a

This work contains parts of the PhD thesis of Dr. V. Wachholz.

Vanessa Wachholz and Al-Hassan M. Mustafa have equal first author contribution.

Oliver H. Krämer

okraemer@uni-mainz.de

Extended author information available on the last page of the article juxtamembrane domain, and an intracellular tyrosine kinase domain (Majothi et al. 2020; Marensi et al. 2021; Scholl et al. 2020). Mutations in FLT3 promote cell growth and chemoresistance and lead to AML with poor prognosis. Internal tandem duplications in FLT3 (FLT3-ITD) occur in $20-35 \%$ of patients with de novo AML and tyrosine kinase domain (FLT3-TKD) mutations occur in 5-10\% of patients with de novo AML (Heidel et al. 2006; Majothi et al. 2020; Marensi et al. 2021; Scholl et al. 2020).

Tyrosine kinase inhibitors (TKi) against hyperactive FLT3 show promising clinical results (Majothi et al. 2020; Marensi et al. 2021; Perl 2019; Scholl et al. 2020). However, during the therapy of AML patients with AC220 (quizartinib), which has a narrow inhibition profile (Zarrinkar et al. 2009), FLT3-TKD mutations arise. 
These disfavor the binding of AC220 (Smith et al. 2012). FLT3-TKD mutations can also adopt conformations that are unfavorable for the binding of broad-acting TKi. For example, the FLT3-N676K mutation disables binding of midostaurin (PKC412) (Heidel et al. 2006), which is approved for the treatment of AML with mutant FLT3 (Majothi et al. 2020; Perl 2019). A newly approved TKi against aberrant FLT3 is the dual FLT3/AXL inhibitor gilteritinib which is far less specific than AC220 (Pulte et al. 2021). We have recently developed the new FLT3 inhibitor (FLT3i) marbotinib which has nanomolar activity against FLT3-ITD, a very narrow inhibitory profile, and activity against FLT3-TKD mutants (Sellmer et al. 2020).

An alternative route to target FLT3 mutants is the induction of their degradation by ubiquitination-mediated proteasomal and lysosomal pathways. Histone deacetylase inhibitors (HDACi) are epigenetic drugs that induce a proteasomal degradation of FLT3-ITD. The underlying mechanism is a transcriptional induction of the E2 ubiquitin conjugase UBCH8 and a phosphorylation-dependent binding of FLT3ITD by the UBCH8-associated SIAH1/SIAH2 E3 ubiquitin ligases (Buchwald et al. 2013). The proteasomal degradation of FLT3-ITD in the presence of HDACi correlates with a decreased interaction of FLT3-ITD with the chaperone HSP90 (Bali et al. 2004; Nishioka et al. 2008). Combined pharmacological inhibition of HDACs and FLT3-ITD synergistically induces apoptotic cell death in AML cells (Bali et al. 2004; Li et al. 2017; Pietschmann et al. 2012). This physiologically important cell death mechanism is controlled by pro- and anti-apoptotic proteins and dismantles cells without debris (Kale et al. 2018). Apoptosis of FLT3ITD positive cells that are exposed to FLT3i and HDACi is linked to a proteasomal and caspase-dependent degradation of FLT3-ITD (Bali et al. 2004; Buchwald et al. 2013; Li et al. 2017; Nishioka et al. 2008; Pietschmann et al. 2012).

The HDAC family comprises classes I-IV (Krämer 2009; Krämer et al. 2014) and four HDACi have been approved by the FDA for the treatment of lymphoma and myeloma. These include the hydroxamic acid derivatives vorinostat (SAHA), panobinostat (LBH589), belinostat (PXD-101), and the depsipeptide FK228 (romidepsin/FR901228/istodax) (Li et al. $2019 b$ ). It is unclear whether a pharmacological inhibition of individual classes of HDACs can interact favorably with specific TKi against leukemic cells with aberrant FLT3 activation. Due to the strong association between class I HDACs and tumor growth and development (Li et al. 2020; Luo and Li 2020), these could be good targets for such an approach. Class I HDACi with reported anticancer activity are the clinically tested entinostat (MS-275), the neurologically used drug valproic acid, and the experimental agents RGFP966 and MERCK60 (Beyer et al. 2019; Blaheta and Cinatl 2002; Krämer 2009; Lakshmaiah et al. 2014).
Beyond the activation of proliferative kinase signaling cascades, mutant FLT3 promotes the expression of DNA repair proteins that antagonize chemotherapy. For example, FLT3-ITD and FLT3-TKD induce the expression of the filament protein RAD51, which supports faithful DNA repair through homologous recombination (HR) (Bagrintseva et al. 2005; Seedhouse et al. 2006). Checkpoint kinases (CHKs) are primary sensors of DNA replication stress and damage, and inhibitors of these enzymes kill AML cells with hyperactive FLT3 (Boudny and Trbusek 2020; Yuan et al. 2014). HDACs and HDACi modulate the expression and the acetylation of DNA repair proteins, and thereby modulate the threshold for lethal DNA damage in cancer cells with chemotherapy-induced stress (Göder et al. 2018; Krumm et al. 2016; Nikolova et al. 2017). In permanent and primary human AML cells with and without FLT3-ITD, HDACi decrease RAD51, CHK1, and the cell cycle regulatory kinase WEE1 (Dai et al. 2013; Li et al. 2019a; Qi et al. 2015; Xie et al. 2013; Zhao et al. 2017; Zhou et al. 2015). Whether a combined application of FLT3i and HDACi alters the levels of DNA repair proteins is not known.

HDACi with a specific inhibitory profile against individual HDACs produce less side effects than pan-HDACi ( $\mathrm{Li}$ et al. 2020; Luo and Li 2020; Müller and Krämer 2010) and could therefore be a good combination partner with FLT3i. We treated AML cells that carry FLT3-ITD with AC220 and HDACi. We used the clinically approved HDACi FK228, which preferentially inhibits class I HDACs (Pojani and Barlocco 2020), and the benzamide-based HDACi RGFP966, which preferentially inhibits HDAC3 (Beyer et al. 2019; Matthews et al. 2015). We analyzed drug-induced apoptosis and replication stress/DNA damage. Combinations of nanomolar doses of AC220 or marbotinib with nanomolar doses of FK228 or micromolar doses of RGFP966 synergistically induced apoptosis and altered cell cycle progression. This cytotoxicity was associated with a loss of survival signaling through FLT3-ITD, a dysregulation of cell cycle and DNA repair proteins, and an accumulation of markers for replication stress and DNA damage.

\section{Materials and methods}

\section{Cell lines and reagents}

Cells were a gift from Prof. Dr. Frank-Dietmar Böhmer, University of Jena, Germany or were from the group of Prof. Dr. Thomas Kindler, Mainz, Germany (cells were originally from the German collection of microorganisms and cell cultures, Braunschweig, Germany). Cell authentication was done by DNA-profiling using eight different, highly polymorphic short tandems repeats (MV4-11, RS4-11, and K562 cells). Cells were maintained at $37{ }^{\circ} \mathrm{C}$ and $5 \% \mathrm{CO}_{2}$ in humidified 
atmosphere. Growth media was RPMI-1640 medium containing 10\% fetal calf serum (FCS, Lonza, Cologne, Germany) and $1 \%$ penicillin/streptomycin (Sigma, Munich, Germany). We used no commonly mischaracterized cell lines. Moreover, cells were confirmed to be free of mycoplasma every 1-4 months. The p53 status of the cells is wild-type for MV411 cells (Yan et al. 2020) and MOLM-13 cells (Thompson et al. 2010), mutant for RS4-11 cells (Demir et al. 2020), null for K562 cells (Pons et al. 2021). Marbotinib has been patented (Mahboobi et al. 2019; Sellmer et al. 2020). MV4-11 cells with an inducible shRNA for HDAC3 were engineered by lentiviral transduction with the Tet-on ${ }^{\circledR}$-inducible lentiviral vector pTRIPZ (Thermo Scientific) encoding the miR-shRNA shHDAC3, clone Id: V3THS_380877; AGAAGTCCACTACCT GGTT. Lentiviral particles were produced by co-transfection of 293FT cells with the psPAX2, pMD2.G, and the lentiviral shRNA HDAC3 vector. Transfections were carried out using TransIT $^{\circledR}$ (Mirus) as per the manufacturer's instructions in the presence of $5 \mu \mathrm{g} / \mathrm{mL}$ polybrene. Following transduction, cells were selected with $1.0 \mu \mathrm{g} / \mathrm{mL}$ puromycin (Sigma-Aldrich).

\section{Flow cytometry}

For viability measurements using DAPI, cells were resuspended and incubated for $5 \mathrm{~min}$ at room temperature in PBS containing $2 \mathrm{mM}$ EDTA and $1 \mu \mathrm{g} / \mathrm{mL}$ DAPI. Cell cycle staining was performed using hypotonic fluorochrome solution (HFS) buffer $(3.88 \mathrm{mM}$ sodium citrate, $0.1 \%(\mathrm{v} / \mathrm{v})$ triton X-100) containing $50 \mathrm{mM}$ PI. Cells were incubated for 15 min in HFS-buffer prior measurement. Cell cycle, subG1 fraction, and annexin-V/propidium iodine (PI) analyses were done according to our recent protocols, see (Beyer et al. 2019; Kiweler et al. 2018, 2020; Pons et al. 2018). Flow cytometry analyses were performed with a FACS Canto II (BD Bioscience, Heidelberg, Germany). FACSDiva 7.0 and FlowJo were used as software tools to evaluate the flow cytometry data.

\section{Synergy calculation}

Synergism was determined using a free software that was designed by the Cancer Research Institute Cambridge, UK. The drug interaction models highest single agent (HSA), Loewe, and Bliss were used to determine synergism scores. Scores are interpreted as antagonistic effects: $x \leq-10$; no interaction effects: $-10 \leq x \leq 10$; synergistic effects: $x \geq 10$.

\section{Protein analyses and immunofluorescence staining for histone H2AX with phosphorylated S139 ( $\mathrm{YH} 2 \mathrm{AX})$}

Immunoblot and immunofluorescence analyses were carried out as described by us recently (Beyer et al. 2019; Pons et al. 2018). The antibodies that we used are listed in Table 1.

\section{Detection of replicating (S phase) cells by 5-ethynyl-2'-deoxyuridine (EdU) incorporation}

EdU incorporation for the detection of $\mathrm{S}$ phase cells was performed using the EdU Click-It Imaging Kit (Thermo Fisher Scientific) according to the manufacturer's instructions, with slight modifications. We used the FAM azide click-it dye from Lumiprobe (Hannover, Germany), as described in (Berte et al. 2016). EdU was given to the cell cultures at a final concentration of $10 \mu \mathrm{M}$. After $1 \mathrm{~h}$ incubation in the incubator (light-protected), cells were washed in PBS and fixed for 10 min onto coverslips at $-20^{\circ} \mathrm{C}$ in an icecold methanol:aceton mixture $(7: 3, \mathrm{v} / \mathrm{v})$. Cells were washed and rehydrated in PBS, and EdU detection was performed according to the manufacturer. Nuclei were counterstained with TO-PRO3 (Invitrogen), which was added to the antifade medium Vectashield (Vector Labs). Representative confocal images were captured by the ZEN2009 software for a laser scanning microscope LSM710 (Carl Zeiss, Germany). Cells

Table 1 List of antibodies used in this study

\begin{tabular}{|c|c|c|}
\hline Antibody & Order number & Company \\
\hline ac-H4 (Lys5) & \#86475 & Cell Signaling \\
\hline ac-H3 (Lys14) & 06-599 & Millipore \\
\hline ac-tubulin (Lys40) & $\mathrm{T} 7451$ & Sigma \\
\hline$\beta$-actin & sc-47778 & Santa Cruz \\
\hline CHK1 & $\# 2360$ & Cell Signaling \\
\hline p-CHK1 (Ser345) & $\# 2344$ & Cell Signaling \\
\hline cleaved caspase- 3 & \#9661 & Cell Signaling \\
\hline ERK1 & $\begin{array}{l}\text { sc-271269 } \\
\text { or } \\
\# 271269\end{array}$ & $\begin{array}{l}\text { Santa Cruz } \\
\text { Cell Signaling }\end{array}$ \\
\hline $\begin{array}{l}\text { p-ERK1(Thr202)/p-ERK2 } \\
(\text { Tyr204) }\end{array}$ & \#9101 & Cell Signaling \\
\hline FLT3 & sc-480 & Santa Cruz \\
\hline p-FLT3 & $\# 3461$ & Cell Signaling \\
\hline HSP90 & sc-13119 & Santa Cruz \\
\hline yH2AX & \#9718 & Cell Signaling \\
\hline PCNA & sc-56 & Santa Cruz \\
\hline p21 (CIP1/WAF1) & ab109520 & Abcam \\
\hline P53 & sc-126 & Santa Cruz \\
\hline RAD51 & ab6380 & Abcam \\
\hline p-RPA (Thr21) & ab661065 & Abcam \\
\hline STAT5 & $\begin{array}{l}\text { sc-74442 } \\
\text { or } \\
\text { BD616191 }\end{array}$ & $\begin{array}{l}\text { Santa Cruz } \\
\text { BD Biosciences }\end{array}$ \\
\hline p-STAT5 (Tyr694) & ma5-14973 & Thermo Fisher \\
\hline thymidylate synthase & \#9045 & Cell Signaling \\
\hline$\alpha$-tubulin & Ab176560 & Abcam \\
\hline UBCH8 & AP2118a & Abgent \\
\hline Vinculin & sc-7336 & Santa Cruz \\
\hline WEE1 & sc-5285 & Santa Cruz \\
\hline
\end{tabular}


A

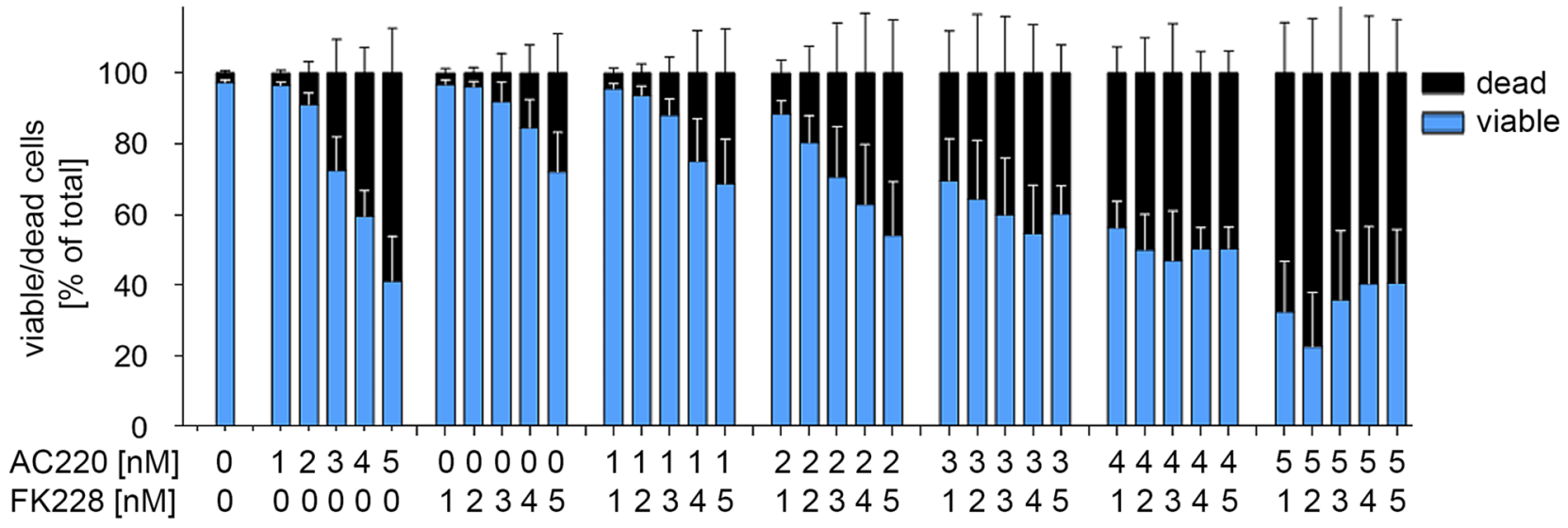

B

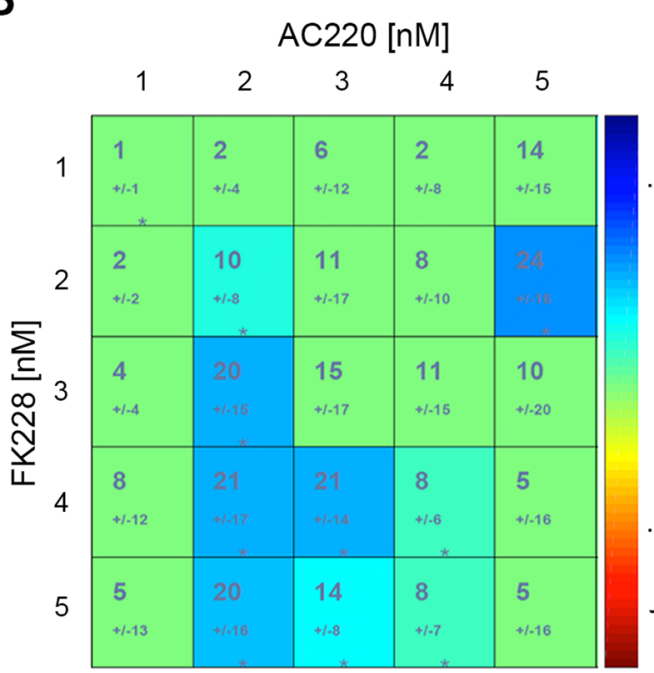

C

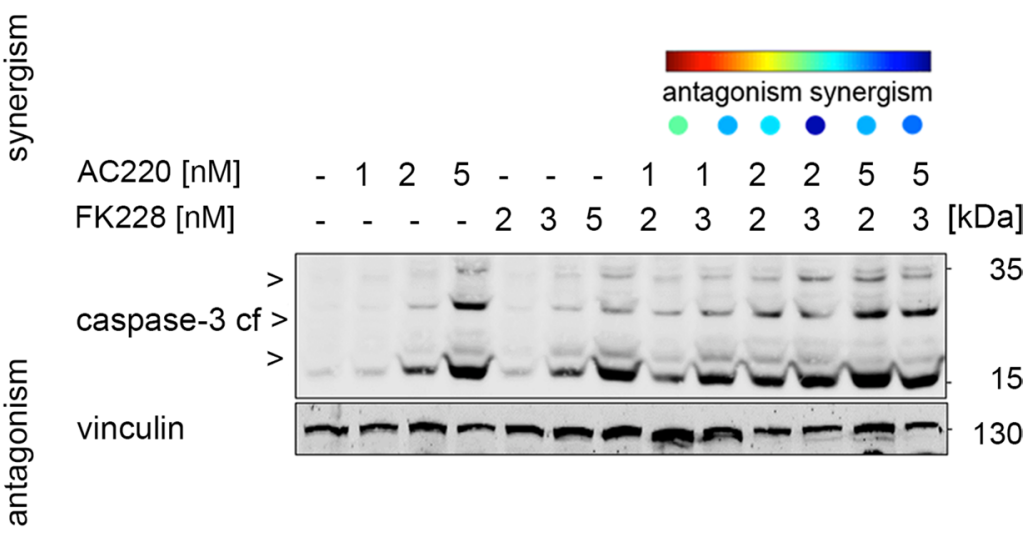

D

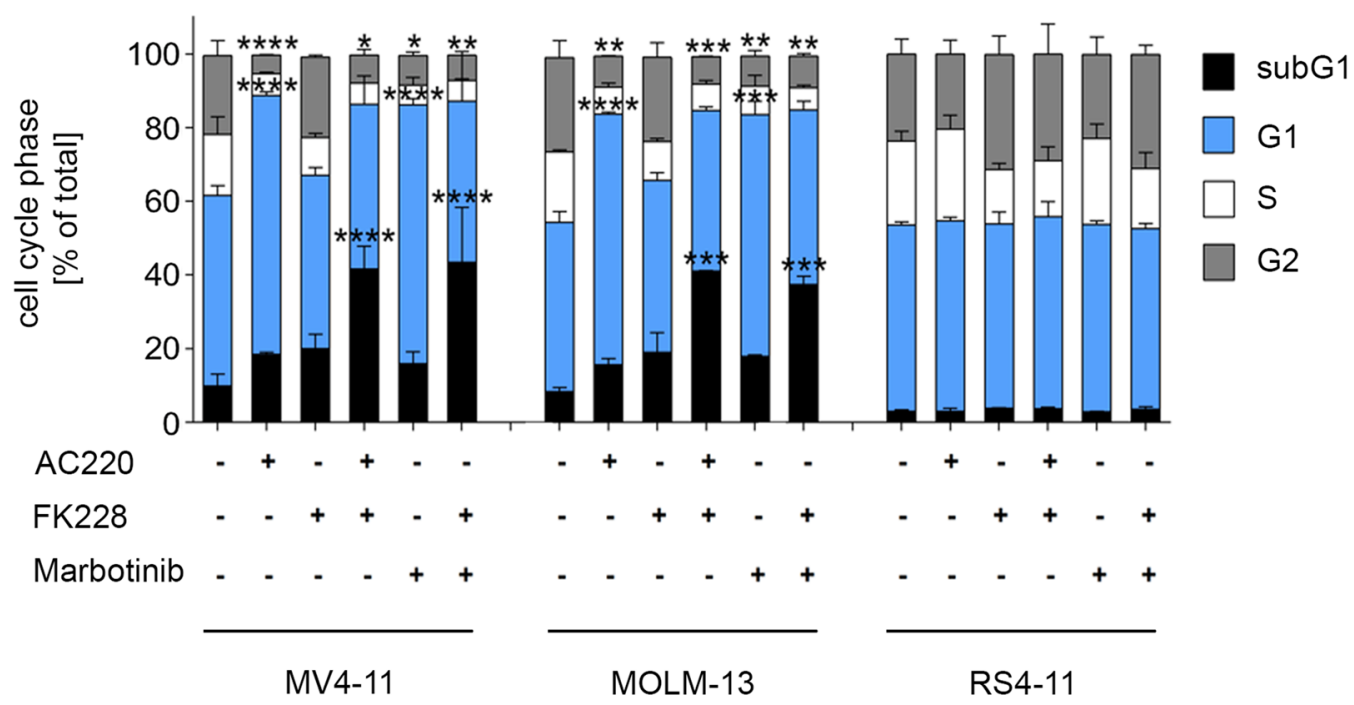


4Fig. 1 FLT3i and FK228 synergistically increase cell death of human leukemic cells with FLT3-ITD. a MV4-11 cells were treated for $24 \mathrm{~h}$ with either AC220 and/or FK228 in doses as indicated. Cells were then stained with DAPI and analyzed by flow cytometry for DAPI incorporation. Bars represent the mean $\pm \mathrm{SD} ; n=6$. b Determination of synergistic mechanism by combining AC220 and FK228 treatment in MV4-11. Synergistic effects were determined by using combenefit software. Using the HSA model, we determined the mean synergistic scores. Calculated scores determine drugs interaction as followed (antagonistic effects: $x \leq-10$; no interaction effects: $-10 \leq x \leq 10$; synergistic effects: $x \geq 10)$. Results represent the mean $\pm \operatorname{SD}(n=6$; HSA). c MV4-11 cells were incubated for $24 \mathrm{~h}$ with either AC220 and/or FK228 in doses as indicated. Immunoblot analysis of whole cell lysates was performed to detect cleaved caspase-3; vinculin served as loading control $(n=3)$. d MV4-11 cells, MOLM-13 cells, and RS4-11 cells were treated with FK228, AC220, or marbotinib for $24 \mathrm{~h}$. Cells were then subjected to flow cytometry analyses for cell cycle distribution and DNA fragmentation $(n=3 ;-$, untreated; +, treated with $2 \mathrm{nM}$ of the above-mentioned drugs)

with the Click-It fluorescent dye bound to EdU in the DNA were counted on LSM images, using the ImageJ software (version $1.51 \mathrm{M} 9$ ).

\section{Results}

\section{Synergistic cytotoxic interaction of AC220 and FK228}

We incubated human AML cells with FLT3-ITD (MV4-11 cells, from a biphenotypic B myelomonocytic leukemia in a 10-year-old male child) with 1-5 nM AC220 and 1-5 nM FK228 for $24 \mathrm{~h}$ ( 36 conditions, 25 combinations of AC220 plus FK228). Tests for cell viability, by flow cytometry for DAPI incorporation as a sign of cytotoxicity, demonstrated that doses starting from $2 \mathrm{nM}$ AC220 and $3 \mathrm{nM} \mathrm{FK} 228$ as well as $3 \mathrm{nM}$ AC220 plus $1 \mathrm{nM}$ FK228 and $1 \mathrm{nM}$ FK228 plus $2 \mathrm{nM}$ AC220 induced cell death (Fig. 1A).

We used the HSA algorithm to investigate whether the cytotoxic effects of AC220 and FK228 against MV4-11 cells are synergistic. We noted that 5 of the 25 combinations synergistically induced DNA-fragmentation. The remaining combinations caused additive cytotoxic effects and no antagonistic effects occurred. $2 \mathrm{nM} \mathrm{AC} 220$ and $3 \mathrm{nM}$ FK228 were the lowest drug concentrations that interacted synergistically against MV4-11 cells (Fig. 1B).

Caspase- 3 is activated by limited proteolysis in apoptotic cells and cleaves key survival proteins (Boice and BouchierHayes 2020). Immunoblot analyses verified that cleaved caspase-3 accumulated dose-dependently in MV4- 11 cells that were incubated with 1,2, and $5 \mathrm{nM} \mathrm{AC} 220$ and 3 and $5 \mathrm{nM}$ FK228. Cells that were treated with synergistically active combinations of AC220 plus FK228, accumulated higher levels of cleaved caspase- 3 than cells that were treated with the single drugs (Fig. 1C).
Next, we assessed the impact of AC220 and FK228 on cell cycle alterations and apoptosis-associated DNA cleavage by flow cytometry. Depending on cell cycle progression, cells have increased DNA content and subsequently increased incorporation of PI. Cells with reduced DNA content are a hallmark of apoptosis and stem from the activation of the caspase-activated DNase CAD. Such cells accumulate as subG1 fraction in flow cytometry analyses (Marx-Blümel et al. 2017). We noted that $2 \mathrm{nM} \mathrm{AC220}$ stalled MV4-11 cells in G1 phase and reduced the number of cells in the $\mathrm{S}$ and G2/M phases. 2 nM FK228 reduced the $\mathrm{G} 1$ and $\mathrm{S}$ phase populations. Combination of the drugs significantly increased the subG1 fraction populations and decreased cells in G2/M phase (Fig. 1D). We observed these cell cycle alterations and the induction of the subG1 fractions similarly in MOLM-13 cells (express FLT3ITD and wild-type FLT3, from a 20-year-old man with AML cells after initial myelodysplastic syndrome) that we treated with $2 \mathrm{nM} \mathrm{AC} 220 \pm 2 \mathrm{nM}$ FK228 (Fig. 1D).

To control whether these cytotoxic effects are specific for AML cells with mutant FLT3, we incubated human leukemic cells with wild-type FLT3 (RS4-11 cells from a 32-year-old woman with acute lymphoblastic leukemia) with FK228 and AC220. Flow cytometry showed that FK228 increased the number of RS4-11 cells in G2/M phase, without an increase of cells in the subG1 phase. These data confirm that RS4-11 cells have a lower sensitivity to HDACi than MV4-11 cells and MOLM-13 cells (Buchwald et al. 2013). Also as expected for a cell line with wild-type FLT3 (Zarrinkar et al. 2009), AC220 had no discernable effect on RS4-11 cells. The combination of FK228 and AC220 did not increase the effects of FK228 (Fig. 1D). We validated our flow cytometry technology with RS4-11 cells that were treated with hydroxyurea. Hydroxyurea induced apoptosis in RS4-11 cells (Supplementary Fig. S1), verifying that the low levels of apoptosis induction by AC220 plus FK228 (Fig. 1D) are not due to a technical limitation.

To corroborate these data with another FLT3i, we treated the three leukemic cell types with 2 nM FK228 and $2 \mathrm{nM}$ marbotinib (Sellmer et al. 2020). As seen with AC220 plus FK228, combinations of FK228 and marbotinib were not toxic for RS4-11 cells (Fig. 1D). Similar as AC220, marbotinib decreased the numbers of cells in $\mathrm{S}$ phase and G2/M phase. In MV4-11 cells and MOLM13 cells, marbotinib plus FK228 induced cytotoxic DNA fragmentation significantly and more effectively than the single drugs (Fig. 1D).

These data illustrate that AC220 and FK228 are low nanomolar inducers of cell death in FLT3-ITD positive leukemic cells and that combinations thereof are superior to the single treatments. 
A

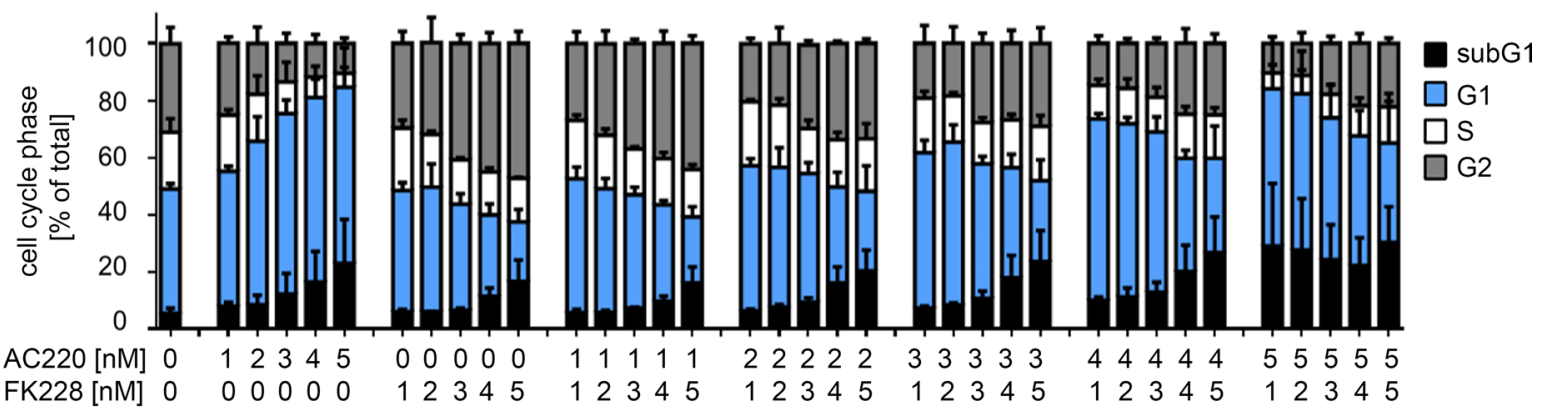

B

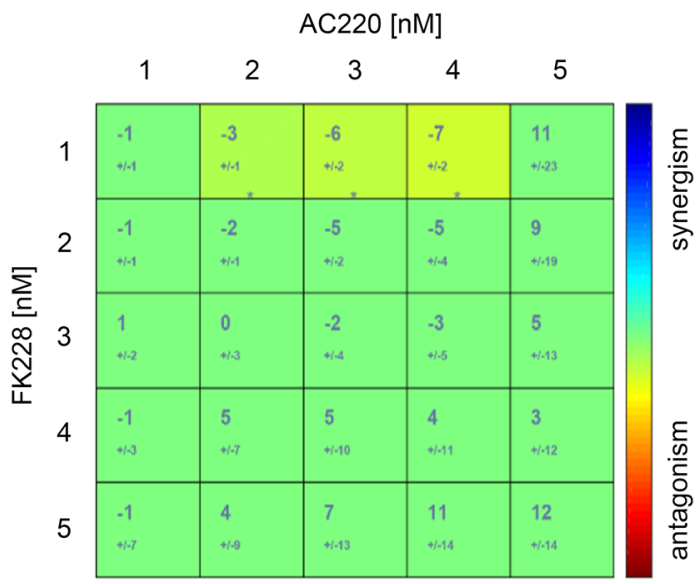

C

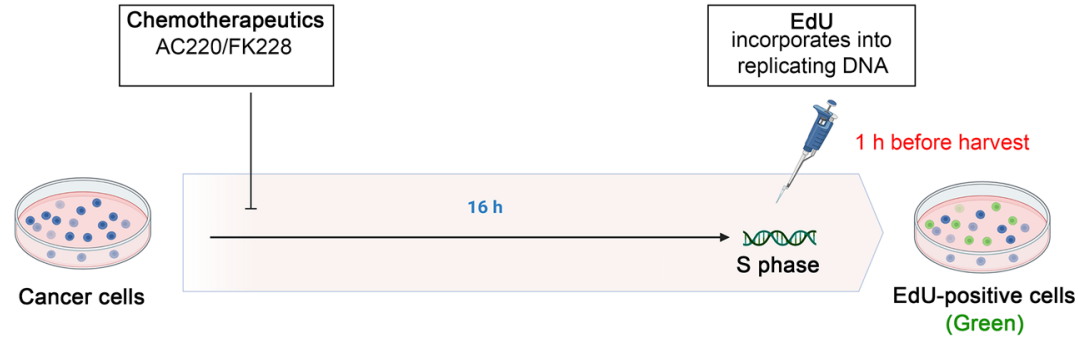

overlay of TO-PRO-3 and EdU
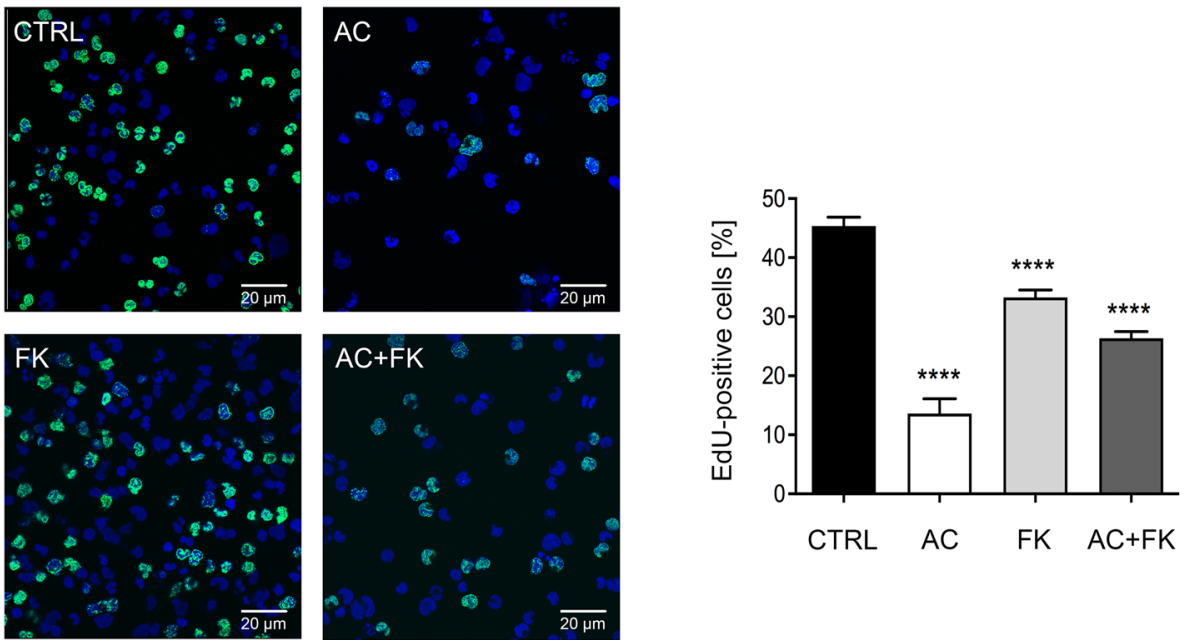
4Fig. 2 FLT3i and HDACi dysregulate cell cycle progression and DNA replication. a MV4-11 cells were treated with single and combined doses of AC220 and FK228 for $16 \mathrm{~h}$ and analyzed for cell cycle distribution. Bars show mean $\pm \mathrm{SD}(n=6)$. b Lack of synergistic mechanism by combining AC220 and FK228 for 16 h in MV411. Effects were determined using combenefit software and the HSA model. Calculated scores determine drugs interaction as followed (antagonistic effects: $x \leq-10$; no interaction effects: $-10 \leq x \leq 10$; synergistic effects: $x \geq 10)$. Results represent the mean $\pm \mathrm{SD}(n=3)$. c We analyzed EdU incorporation as indicated in the scheme. We treated MV4-11 cells for $16 \mathrm{~h}$ with $2 \mathrm{nM} \mathrm{AC220 \pm 3} \mathrm{nM}$ FK228. Cells were pulse labeled with $10 \mu \mathrm{M}$ EdU for $1 \mathrm{~h}$ before harvest. Cells were counterstained using TO-PRO3; scale bar represents $20 \mu \mathrm{m}$. Images are representative for three independent experiments with a similar outcome. The graphs show the EdU-positive cells; $* * * * p<0.0001$

\section{AC220 and FK228 induce different types of cell cycle arrest}

Since the high rates of cell death induction in AC220 plus FK228 treated MV4-11 cells (Fig. 1A-C) may blur drug-induced cell cycle effects, we tried to identify time points at which the drugs produce cell cycle alterations without excessive killing. Flow cytometry showed that after $16 \mathrm{~h}$-exposures, most single and combinatorial drug applications caused less than $20 \%$ accumulation of subG1 fractions in MV4-11 cell cultures (Fig. 2A) and there were no synergistic cytotoxic drug effects (Fig. 2B).

We additionally analyzed cell cycle effects of the drugs by the analysis of the incorporation of the thymidine analog EdU, which occurs during S phase (Fig. 2C). Immunofluorescence demonstrated EdU incorporation in $45 \%$ of untreated MV4-11 cells. Cells treated with $3 \mathrm{nM}$ AC220 for $16 \mathrm{~h}$ incorporated significantly less EdU, reaching 14\% EdU-positive cells (Fig. 2C). This is consistent with the observed G1 phase arrest of MV4-11 cells that are exposed to AC220 (Fig. 2A). Upon FK228 treatment, we noted that $33 \%$ of MV4-11 cells incorporated EdU but also larger cells with a particularly bright EdU staining (Fig. 2C). The occurrence of such cells corresponds to an increase in cells that are in G2/M phase after S phase upon the treatment with FK228 (Fig. 2A). In the cotreatment scheme, we observed $26 \%$ of EdU-positive MV4-11 cells (Fig. 2C), corresponding to the differing effects of AC220 and FK228 on cell cycle arrest in G1 phase or G2/M phase (Fig. 2A).

We conclude that AC220 and FK228 have opposite effects on cell cycle progression, with AC220 inducing a G1 phase arrest and FK228 inducing a G2/M phase arrest. Combinations of these drugs dose-dependently antagonize the cell cycle arrests that the single drugs cause.
AC220 and FK228 promote their target engagement and attenuate DNA repair proteins

Having assessed how AC220 and FK228 affect cell cycle progression and the survival of FLT3-ITD positive cells, we tested how these drugs modulate their targets with the immunoblot method. We first analyzed FLT3-ITD signaling. AC220 and FK228 dose-dependently suppressed the autophosphorylation of FLT3-ITD at Y591 and the phosphorylation of its downstream targets STAT5 at Y694 (p-STAT5) and ERK1/ERK2 at T202 and Y204 (p-ERK1/p-ERK2). These effects were potentiated in the combination schemes (Fig. 3A). This finding reflects the synergistic drug interaction that we observed by flow cytometry. The reduction of FLT3-ITD is associated with an accumulation of UBCH8 (Fig. 3A) which accelerates the proteasomal degradation of phosphorylated FLT3 (Buchwald et al. 2013). We further noted a decrease in STAT5 protein expression (Fig. 3A) which is likely due to its caspase-mediated cleavage (Kosan et al. 2013).

The cyclin-dependent kinase inhibitor p21, which controls cell cycle progression, is induced by FK228 in leukemic and solid tumor cells (Sasakawa et al. 2002) and reduced by AC220 in FLT3-ITD positive leukemic cells (Abe et al. 2016). Consistent with these reports, we found that AC220 reduced p21 expression dose-dependently in MV4-11 cells. FK228 increased p21 levels and AC220 dose-dependently rescinded this effect (Fig. 3A). This correlates with a decrease in the FK228-induced G2/M phase arrest when AC220 is co-added (Fig. 2).

An accumulation of $\gamma \mathrm{H} 2 \mathrm{AX}$ is a marker for replication stress, DNA damage, and apoptosis (Kopp et al. 2019; Rogakou et al. 2000). Our data show an increase of $y \mathrm{H} 2 \mathrm{AX}$ in MV4-11 cells that were treated with $5 \mathrm{nM}$ AC220 or $5 \mathrm{nM}$ FK228. Synergistic combinations of AC220 and FK228 augmented the accumulation of $\mathrm{\gamma H} 2 \mathrm{AX}$ by the single agents. We noted this detectably with 1-2 nM AC220 plus 2-3 nM FK228 and 2 nM AC220 plus 3 nM FK228. These drug combinations induced the accumulation of $\mathrm{yH} 2 \mathrm{AX}$ like $5 \mathrm{nM}$ AC220 and $5 \mathrm{nM} \mathrm{FK} 228$ did (Fig. 3A).

These data let us consider a dysregulation of DNA repair protein expression. The tyrosine kinase WEE1 controls $S$ phase and prevents premature mitosis in the presence of damaged DNA (Elbaek et al. 2020; Ghelli Luserna di Rora et al. 2020), the filament protein RAD51 promotes DNA repair through HR (Grundy et al. 2020), and CHK1 is a primary sensor of replication stress and DNA damage (Boudny and Trbusek 2020; Yuan et al. 2014). We noted that single and combined application of AC220 and FK228 reduced WEE1 and RAD51 dose-dependently. The synergistic combination of $2 \mathrm{nM}$ AC220 and $3 \mathrm{nM}$ FK228 attenuated WEE1 and RAD51 as effectively as $5 \mathrm{nM}$ AC220 and $5 \mathrm{nM}$ FK228 did (Fig. 3A). AC220 also reduced CHK1 expression, while 


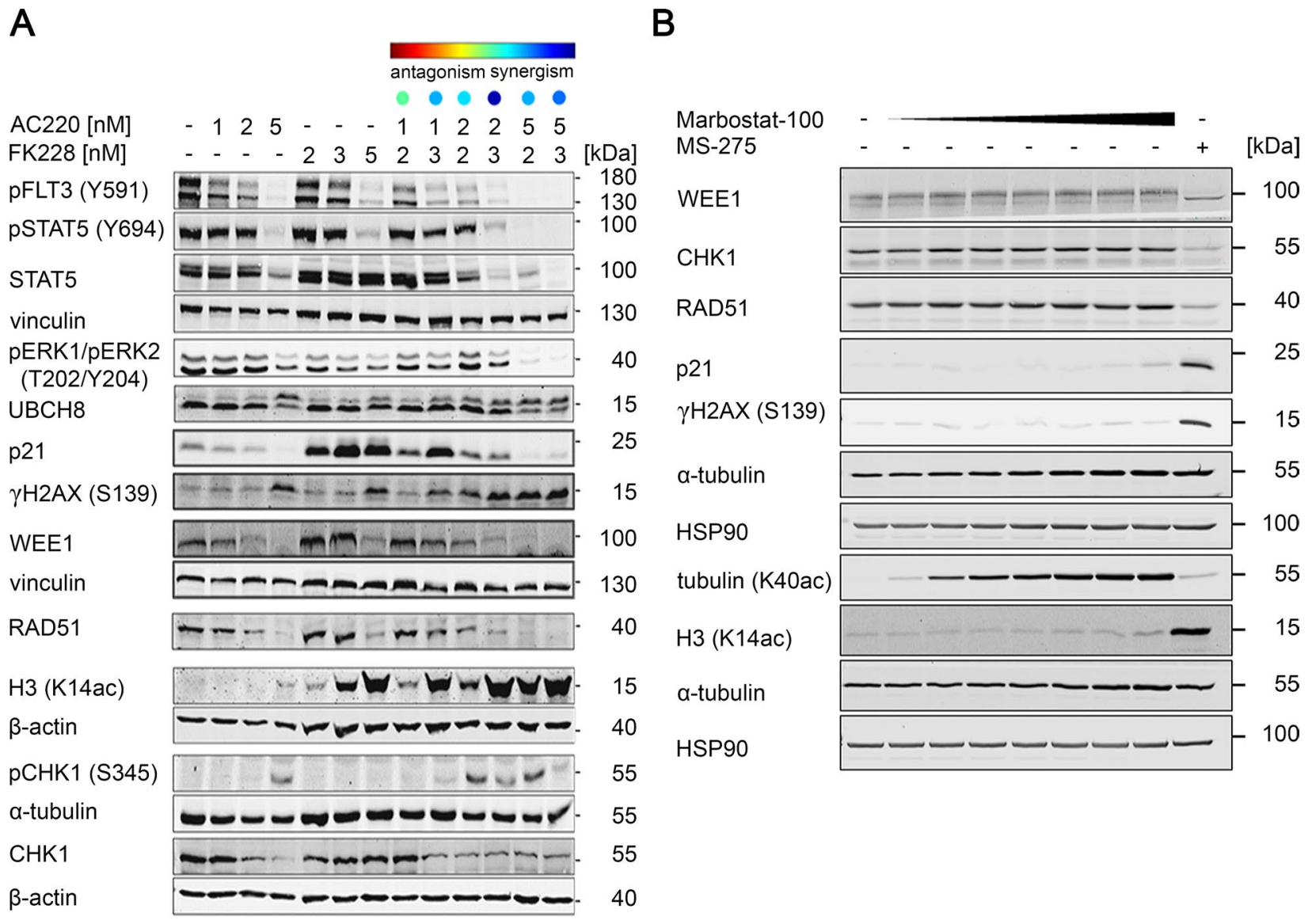

C
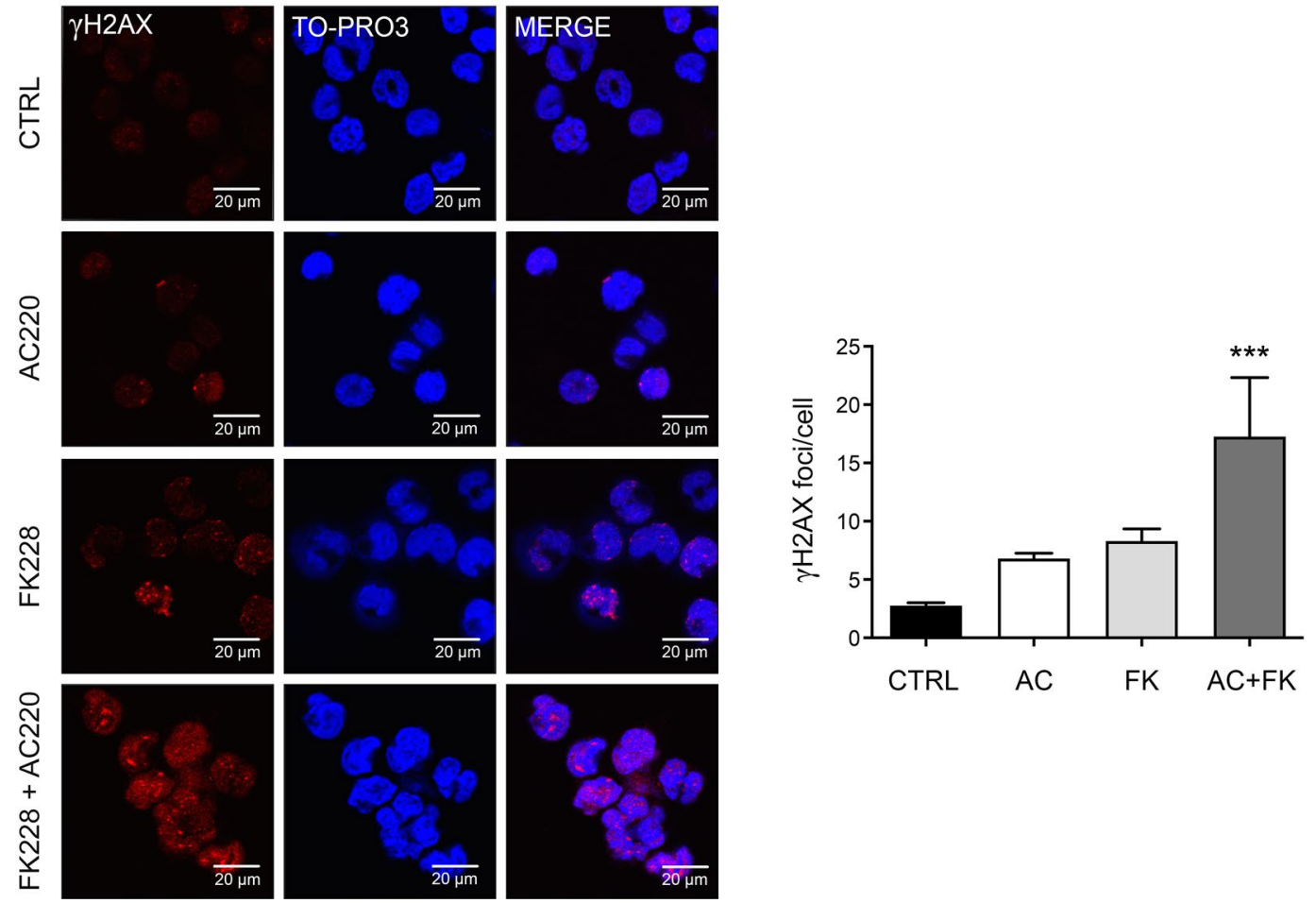
4Fig. 3 Combining FLT3i and HDACi disrupts FLT3 signaling, attenuates DNA repair protein expression, and increases histone $\mathrm{H} 3$ acetylation. a MV4-11 cells were incubated for $24 \mathrm{~h}$ with either AC220 or FK228 as indicated. Immunoblot analyses were performed to detect FLT3-ITD and its downstream signaling, UBCH8, RAD51, yH2AX (S139), histone H3 acetylation, WEE1, phosphorylated CHK1 (S345), and CHK1; Vinculin, $\alpha$-tubulin and $\beta$-actin served as loading control $(n=3)$. b MV4-11 cells were incubated with 5, 20, 50, $100,250,500$, or $1000 \mathrm{nM}$ marbostat -100 or $5 \mu \mathrm{M}$ entinostat for $24 \mathrm{~h}$. Immunoblot was done as indicated $(n=2)$. c MV4-11 cells were left untreated or subjected to with $2 \mathrm{nM} \mathrm{AC} 220 \pm 3 \mathrm{nM} \mathrm{FK} 228$ for $16 \mathrm{~h}$. Cells were stained for $\mathrm{\gamma H} 2 \mathrm{AX}$ foci and nuclei were counterstained by TO-PRO3; scale bar represents $20 \mu \mathrm{m}$. Foci were quantified using Image $\mathbf{J}$ software. Images are representative for 3 independent experiments; $* * * p<0.001$

FK228 had no significant impact on CHK1. Synergistically toxic combinations of AC220 and FK228 likewise reduced CHK1. This reduction of total CHK1 was associated with its activating phosphorylation at S345 (Fig. 3A). This posttranslational modification is catalyzed by the replication stress/ DNA damage activated checkpoint kinase ATR (Boudny and Trbusek 2020; Yuan et al. 2014).

As expected from the literature (Beyer et al. 2017; Li et al. 2019b), FK228 dose-dependently induced the hyperacetylation of histone $\mathrm{H} 3$ when given alone and in combination with AC220. Curiously, the accumulation of acetylated histone H3 by FK228 was augmented by AC220 (Fig. 3A).

FK228 preferentially inhibits class I HDACs, but it is also active against HDAC6 $\left(\mathrm{IC}_{50} \mathrm{HDAC} 1 / 2 / 3=0.00005\right.$; $\mathrm{IC}_{50} \mathrm{HDAC} 8=0.003 ; \mathrm{IC}_{50}$ HDAC6 $=0.01$ ) (Bradner et al. 2010; Noack et al. 2017). The class IIB deacetylase HDAC6 is frequently dysregulated in leukemic cells (Krämer et al. 2014). To test whether the attenuation of CHK1, WEE1, and RAD51 and the accumulation of p21 and $\mathrm{y}_{\mathrm{H}} \mathrm{AX}$ are due to class I or class IIB HDAC inhibition by FK228, we applied the novel, highly specific HDAC6 inhibitor marbostat-100 (Beyer et al. 2019; Noack et al. 2017; Sellmer et al. 2018) to MV4-11 cells. $5 \mathrm{nM}$ to $1 \mu \mathrm{M}$ marbostat-100 dose-dependently induced a hyperacetylation of the HDAC6 target tubulin, but marbostat-100 did not modulate CHK1, WEE1, RAD51, p21, and yH2AX. In contrast, the HDACi entinostat, which specifically inhibits HDAC1, HDAC2, and HDAC3 (Bradner et al. 2010; Noack et al. 2017) attenuated CHK1, WEE1, and RAD51, and induced an accumulation of acetylated histone H3, p21, and yH2AX (Fig. 3B). Hence, HDAC1, HDAC2, and HDAC3 appear as key, druggable regulators of these proteins.

The accumulation of $y \mathrm{H} 2 \mathrm{AX}$ foci indicates DNA damage foci and pan-staining for $\mathrm{\gamma}$ H2AX occurs during apoptosis (Kopp et al. 2019; Rogakou et al. 2000). Confocal immunofluorescence microscopy revealed an accumulation of $\mathrm{yH} 2 \mathrm{AX}$ foci after a $16 \mathrm{~h}$ treatment with $2 \mathrm{nM} \mathrm{AC} 220$ and $3 \mathrm{nM}$ FK228. This effect became significant in the cotreatment scheme (Fig. 3C). There is no significant induction of apoptosis-associated DNA fragmentation after $16 \mathrm{~h}$ (Fig. 2A). This shows that the accumulation of ${ }_{\gamma} \mathrm{H} 2 \mathrm{AX}$ in response to $2 \mathrm{nM} \mathrm{AC} 220$ and $3 \mathrm{nM}$ FK228 is a typical marker for DNA double strand breaks and not a mere readout of apoptosis.

These results show that AC220 and FK228 act on-target. A dysregulation of WEE1, RAD51, and CHK1, together with CHK1 activation, correlates with the accumulation of the DNA damage marker $y \mathrm{H} 2 \mathrm{AX}$ in leukemic cells that are treated with AC220 and FK228.

\section{AC220 and RGFP966 synergistically kill FLT3-ITD positive leukemic cells}

The benzamide HDACi RGFP966 preferentially inhibits HDAC3, and this is sufficient to induce apoptosis of leukemic cells (Beyer et al. 2019). We investigated whether a preferential inhibition of HDAC 3 interacts with AC220 against MV4-11 cells. We applied 1-5 nM AC220 and 0.5-10 $\mu \mathrm{M}$ RGFP966 and 50 combinations thereof (66 conditions). Flow cytometry analyses for live/dead cells with DAPI demonstrated that AC220 and RGFP966 dose-dependently killed MV4-11 cells and that this was potentiated when the compounds were applied together (Fig. 4A). 15 of 50 combination killed MV4-11 cells highly synergistically. $3 \mathrm{nM}$ AC220 plus $6 \mu$ M RGFP966 were the lowest drug concentrations that interacted synergistically (Fig. 4B).

The measurement of cell cycle distributions and subG1 fractions showed that RGFP966 dose-dependently reduced the numbers of $\mathrm{G} 2 / \mathrm{M}$ phase cells and caused the accumulation of cells in subG1 (Fig. 4C). Addition of AC220 dosedependently increased the subG1 fractions (Fig. 4C). This is coherent with the results that are shown in Fig. 4A.

While FK228 caused an accumulation of MV4-11 cells in G2/M phase (Fig. 2A), RGFP966 stalled these cells in G1 phase (Fig. 4C). We asked whether lower doses of RGFP966 may induce an arrest of MV4-11 cells in the G2/M phase. $50 \mathrm{nM}$ RGFP966 slightly increased an accumulation of MV4-11 cells in G2/M phase, but this was not seen with any of the other concentrations that we applied to these cells (Fig. 4D).

We tested the apoptosis induction by AC220 and RGFP966 with an independent apoptosis assay. We used annexin-V/PI staining to detect early apoptosis (annexin$\mathrm{V}$ positive due to a binding to phosphatidyl-serine at the plasma membrane of apoptotic cells) and late apoptosis (annexin-V and PI positive) (Marx-Blümel et al. 2017). We incubated MV4-11 cells, MOLM-13 cells, RS4-11 cells, and K562 cells (from a 53-year-old woman with chronic myeloid leukemia, FLT3 null) with $2 \mathrm{nM}$ AC220 and $1 \mu$ M RGFP966 for $24 \mathrm{~h}$. AC220 and RGFP966 induced apoptosis significantly in MV4-11 and MOLM-13 cells but not in RS4-11 and K562 cells (Fig. 4E). 
A

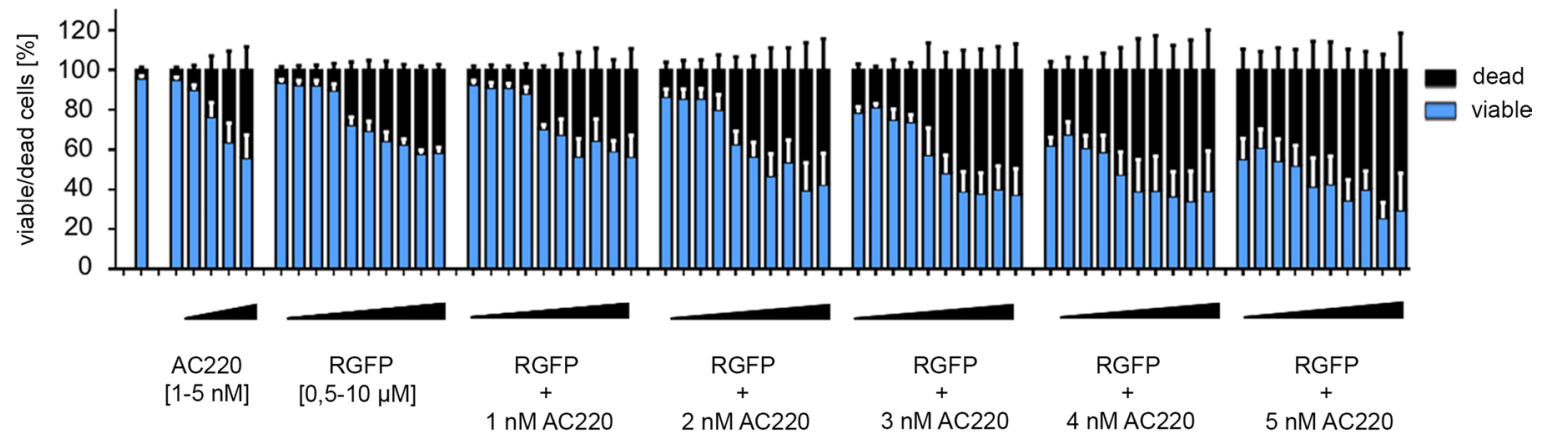

B

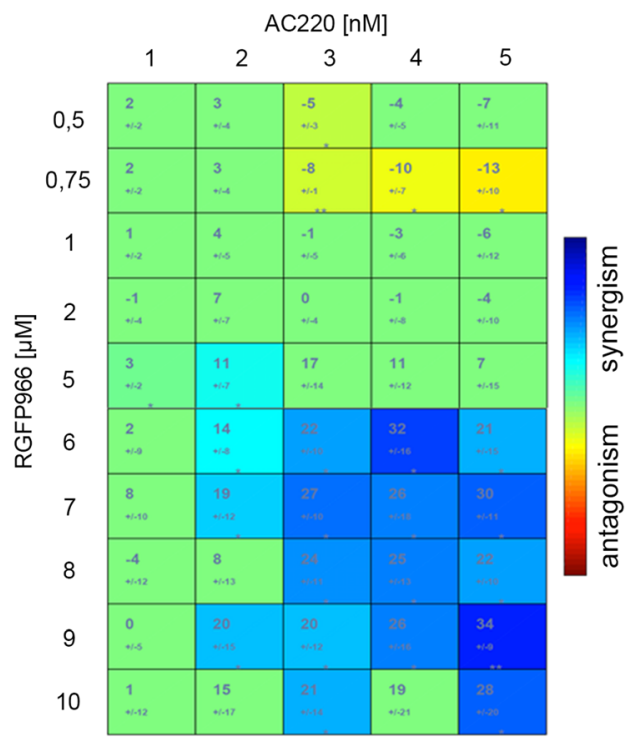

C

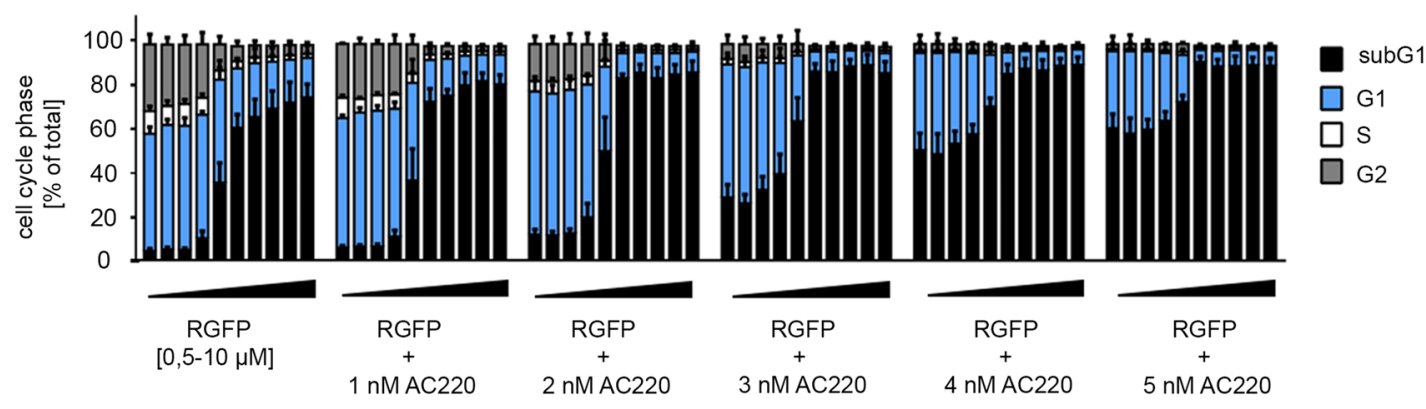

D

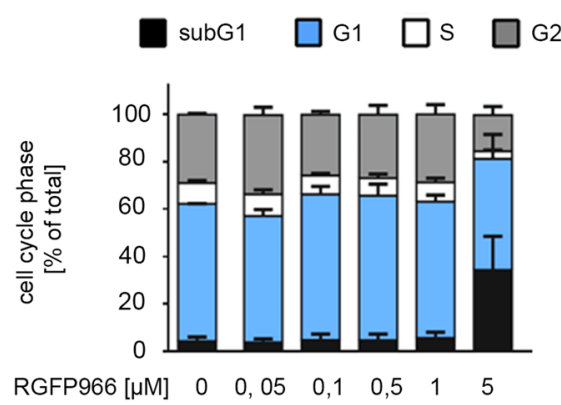

E

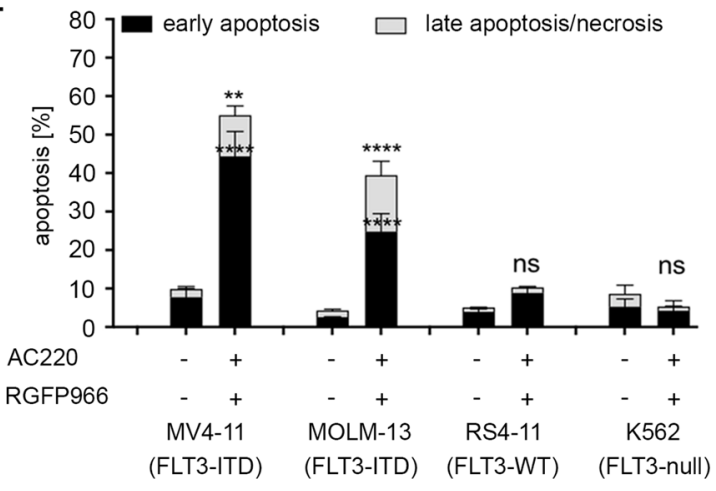


4Fig. 4 Inhibition of HDAC3 and AC220 are synergistically lethal for FLT3-ITD positive leukemic cells. a MV4-11 cells were incubated for $24 \mathrm{~h}$ with either $1,2,3,4$, or $5 \mathrm{nM} \mathrm{AC220}$ and/or $0.5,0.75,1$, $2,5,7,8,9$, or $10 \mu \mathrm{M}$ RGFP966 (increasing doses from left to right shown by the black triangles). Cells were then stained with DAPI and analyzed by flow cytometry for DAPI incorporation. Results represent the mean $\pm \mathrm{SD}(n=5)$. b Determination of synergistic mechanism by combining AC220 and RGFP966 treatment in MV4-11. Synergistic effects were determined by using combenefit software. Using the HSA model, we determined the mean synergistic scores. Calculated scores determine drugs interaction as followed (antagonistic effects: $x \leq-10$; no interaction effects: $-10 \leq x \leq 10$; synergistic effects: $x \geq 10)$. Results represent the mean \pm SD $(n=5$; HSA). c MV4-11 cells were treated with $0.5,0.75,1,2,5,6,7,8,9$, or $10 \mu \mathrm{M}$ RGFP966 $\pm 1,2,3,4$, or $5 \mathrm{nM}$ AC220 for $24 \mathrm{~h}$ (increasing doses from left to right shown by the black triangles). Cells were stained with PI and analyzed by flow cytometry for different cell cycle phases. Bars show mean \pm SD $(n=5)$. d MV4-11 cells were treated with $0.05,0.1$, $0.5,1$, or $5 \mu \mathrm{M}$ RGFP966 for $24 \mathrm{~h}$ and were analyzed as mentioned in a) **** $p<0.0001(n=2)$. e MV4-11, MOLM-13, RS4-11, and K562 cells were treated with $2 \mathrm{nM} \mathrm{AC} 220+1 \mu \mathrm{M}$ RGFP966 for $24 \mathrm{~h}(-$, untreated). Cells were stained for annexin-V/PI and analyzed by flow cytometry. Graph represents mean values \pm SD of independent experiments; $* * p<0.01 ; * * * p<0.0001(n=3)$

These data illustrate, that combinations of AC220 plus RGFP966 combine favorably against leukemic cells with FLT3-ITD.

\section{AC220 and RGFP966 promote their target engagement and attenuate DNA repair proteins}

Next, we carried out a biochemical assessment of the interactions of AC220 and RGFP966. We used two concentrations of AC220, five concentrations of RGFP966, and six combinations thereof. AC220 suppressed the phosphorylation of FLT3-ITD at Y591, without reducing total FLT3ITD. The ratio between the upper, hyperglycosylated and the lower, hypoglycosylated and hyperactive form of FLT3-ITD increased towards the upper band (Fig. 5A). This finding and the suppressed phosphorylation of FLT3-ITD validate the anticipated effects of AC220 (Majothi et al. 2020; Marensi et al. 2021; Scholl et al. 2020). RGFP966 reduced the levels of FLT3-ITD, and this was associated with a reduction of pY591-FLT3-ITD. Combinations of AC220 and RGFP966 potentiated their suppressive effects on FLT3-ITD and the levels of total and phosphorylated FLT3-ITD tied in with the degree of synergistic pro-apoptotic drug interactions. The inhibitory effects of these agents on FLT3-ITD led to a decreased phosphorylation of its targets ERK1/ERK2 (Fig. 5A).

Regarding their effects on replication stress/DNA damage proteins, AC220 and RGFP966 reduced WEE1 and CHK1 dose-dependently and this was potentiated in the cotreatment scheme. The strongest attenuation of WEE1 and CHK1 correlated with the highest levels of synergistic killing of MV411 cells (Fig. 5A). The accumulation of single-stranded
DNA activates checkpoint kinases which activates the single strand DNA binding protein RPA by phosphorylation on T21 (Anantha et al. 2007). Both RPA phosphorylated on T21 and yH2AX were increased dose-dependently by RGFP966 and AC220. All combinations thereof led to increased signals of phosphorylated RPA and H2AX as well as cleaved caspase-3 (Fig. 5A). This confirms that these agents induce DNA damage and apoptosis.

Like FK228, RGFP966 dose-dependently increased p21 and $1 \mathrm{nM}$ AC220 was sufficient to block the RGFP966 induced accumulation of p21 (Fig. 5A). As seen with FK228 and AC220 for histone H3 acetylation (Fig. 3A), the dose-dependent accumulation of acetylated histone $\mathrm{H} 4$ by RGFP966 was augmented by AC220 (Fig. 5A).

To corroborate these data with a genetic model, we transduced MV4-11 cells with an inducible shRNA against HDAC3. The knockdown of HDAC3 attenuated RAD51, WEE1, and CHK1 (Fig. 5B).

Since RAD51 and CHK1 are regulated by mutant FLT3 (Bagrintseva et al. 2005; Kurosu et al. 2013) and by the cell cycle (Nikolova et al. 2017), we additionally probed immunoblots for the general DNA synthesis protein proliferating cell nuclear antigen (PCNA) and for thymidylate synthase (TS). Like RAD51, CHK1, and WEE1 (Figs. 3A, 5A), TS was also decreased by AC220, but this was not potentiated by FK228 and RGFP966. PCNA was not affected by any of these drugs (Fig. 5C).

Given that the transcription factor p53 promotes the expression of p21 in leukemic cells (Yan et al. 2020), we speculated that the reduction of $\mathrm{p} 21$ expression by AC220 (Figs. 3A, 5A) is associated with a decrease of p53. Indeed, AC220 decreased p53. FK228 and RGFP966 did not alter p53 levels but augmented the suppressive effect of AC220 on p53 (Fig. 5C).

These data illustrate that AC220 and RGFP966 act ontarget and that they dysregulate cell cycle progression and proteins that control cellular responses to replication stress and DNA damage. AC220 and RGFP966 potentiate their specifically effects on signaling pathways and HDAC3 is necessary for the expression of DNA repair proteins in leukemic cells.

\section{Discussion}

AML with FLT3-ITD mutations shows poor responses to current therapeutic approaches. Improved TKi as well as rationally defined combinatorial treatments can be milestones for the management of this disease. This could render FLT3-ITD positive AML into a curable disease. This has been achieved for most cases of acute promyelocytic leukemia which is driven by the leukemia fusion protein PML-RAR $\alpha$ (Perl 2019). In FLT3-ITD positive 
A

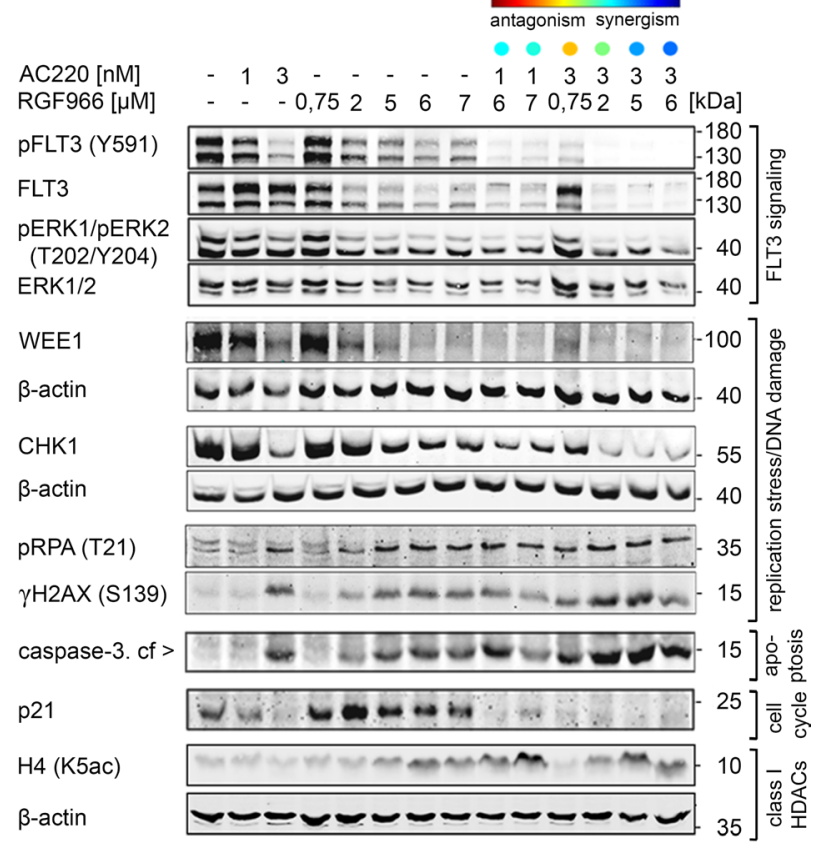

B

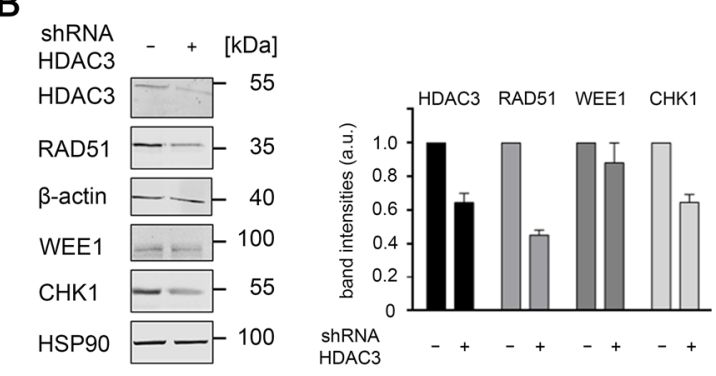

C

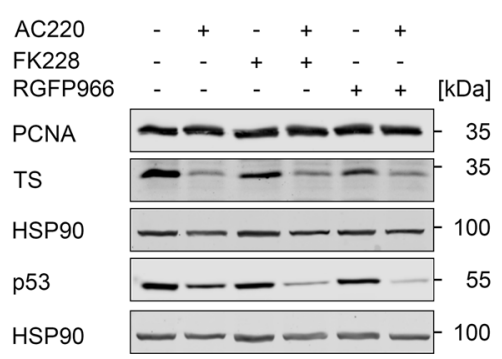

Fig. 5 Simultaneous Inhibition of FLT3-ITD and HDAC3 disrupts FLT3 signaling, DNA repair and increases DNA damage. a MV4-11 cells were incubated for $24 \mathrm{~h}$ with either AC220 and/or RGFP966 in the stated doses. Immunoblot analyses were performed to detect the indicated proteins of FLT3 signaling pathway; $\beta$-actin served as loading control for all blots $(n=3)$. b MV4-11 cells with an inducible knockdown of HDAC3 by shRNAs were treated with doxycycline for $48 \mathrm{~h}$ (-, untreated; + , treated). Lysates of these cells were analyzed as indicated. Band intensities were measured from 2-3 independent immunoblot experiments (a.u., arbitrary units). c MV4-11 cells were left untreated (-) or treated with $2 \mathrm{nM} \mathrm{AC} 220 \pm 3 \mathrm{nM}$ FK228 or $1 \mu \mathrm{M}$ RGFP966 for $24 \mathrm{~h}$. Cell lysates were analyzed by immunoblot for PCNA, TS, p53, with HSP90 as loading controls. Results are representatives of two independent experiments leukemic cells that are treated with AC220 or marbotinib plus FK228 or RGFP966, we observe an increase of the cell populations that accumulate DAPI and PI, that have phosphatidylserine on their cell surface, and that display cleaved caspase- 3 . These are typical markers of cell death, with the activation of caspase- 3 being a point of no return for the demise of cells by apoptosis (Boice and Bouchier-Hayes 2020). Thus, our data demonstrate that such drug combinations eliminate cells with mutated FLT3 through apoptosis. Leukemic cells with wild-type FLT3 are thought unaffected by these drugs, suggesting selectivity for cells with mutant FLT3. Analysis of a larger cell line panel is necessary to verify this hypothesis.

Inhibitors of FLT3-ITD and HDACi are known to cause cell cycle arrest (Li et al. 2020; Luo and Li 2020; Majothi et al. 2020; Marensi et al. 2021; Scholl et al. 2020). FK228 induced p21 and cell cycle arrest in G2/M phase. AC220 suppresses p21 expression and arrests cells in G1 phase. Moreover, AC220 antagonizes the induction of p21 in FK228-treated MV4-11 and attenuates the FK228induced $\mathrm{G} 2 / \mathrm{M}$ phase arrest. These data suggest that $\mathrm{p} 21$ is required to stall FK228-treated MV4-11 cells in G2/M phase. In contrast to FK228, RGFP966 induces p21 and an accumulation of cells in G1 phase. These differences may be due to the differences in the inhibitor profiles. While the benzamide RGFP966 preferentially inhibits HDAC 3 over HDAC1/HDAC2, FK228 additionally blocks HDAC8 (Beyer et al. 2019; Matthews et al. 2015; Pojani and Barlocco 2020). Inhibition of HDAC8 increases the acetylation of the structural maintenance of chromosomes protein-3 (Deardorff et al. 2012) and this may contribute to the G2/M arrest in FK228-treated MV4-11 cells. This idea is supported by the finding that a specific inhibition of HDAC8 with the compound PCI-34051 can delay cell cycle progression of breast cancer cells (Dasgupta et al. 2016).

AC220 suppresses p21 expression and prevents the accumulation of $\mathrm{p} 21$ in response to HDACi. This mechanism could be pro-apoptotic because p21 suppresses caspase- 3 activation in HDACi-treated tumor cells (Krämer et al. 2008; Rosato et al. 2003, 2004). Consistent herewith, we show that a reduction of p21 is associated with increased apoptosis induction in leukemic cells. This does not imply that an induction of p21 by FK228 and RGFP966 prevents apoptosis induction per se. Concomitant induction of p21 and of apoptosis by HDACi occurs in various other cancer cells; for example, in acute lymphoid leukemia and chronic myeloid leukemia cells that are treated with the depsipeptide spiruchostatin B (Kanno et al. 2012) and in solid tumor cells (Wang et al. 2012) and histiocytoma cells (Sasakawa et al. 2002) that are treated with FK228. The increase of p21 in MV4-11 cells is not linked to an increase in p53 levels. This can be explained 
by sufficient levels of basal p53, and it needs to be considered that class I HDACs critically control p53 by direct lysine acetylation (Marx et al. 2021).

The data above provide two not mutually exclusive explanations for the inhibitory effect of AC220 on p21 expression. First, we observed a loss of p53 which was recently shown to promote the expression of p21 in FK228-treated MV4-11 cells (Yan et al. 2020). Second, we noted that AC220 activates CHK1 which has a suppressive effect on the translation of the p21 mRNA (Beckerman et al. 2009).

We further noted a pronounced target engagement of the AC220 and the HDACi. FK228 and RGFP966 potently reduce FLT3-ITD and AC220 augments this effect. These data are consistent with the reported degradation of FLT3ITD upon a treatment with entinostat, which specifically inactivates HDAC1, HDAC2, and HDAC3 (Nishioka et al. 2008). Moreover, we here confirm our data for FLT3-ITD positive AML cells that are treated with combinations of panobinostat plus AC220 (Pietschmann et al. 2012) and extend them by showing a survival dependency of FLT3itreated leukemic cells on HDAC3.

Secondary mutations of FLT3-ITD in its TKD are selected during the therapy with AC220. These mutated cells are more resistant than FLT3-ITD against AC220 and cause relapse and poor patient prognosis (Antar et al. 2020; Perl 2019). We recently presented marbotinib as specific inhibitor of FLT3-ITD and FLT3-TKD oncogenes (Sellmer et al. 2020). We show here that AC220 combines favorably with the FDA-approved HDACi FK228 against leukemic cells carrying FLT3-ITD. Hence, the administration of marbotinib and class I HDACi may be a valid strategy against leukemic cells with FLT3-TKD mutants.

Surprisingly, AC220 increased the HDACi-induced accumulation of acetylated histones $\mathrm{H} 3 / \mathrm{H} 4$. We can only speculate whether this is a consequence of cell death, a modulation of HDACs and histone acetyltransferases, or alterations in the cellular pool of free acetyl-CoA due to altered mitochondrial metabolism.

This work further reveals that AC220 plus HDACi reduce the levels of CHK1, WEE1, RAD51, and TS. These findings support previous data on a loss of CHK1, WEE1, and RAD51 in leukemic cells in vitro and in vivo when they are treated with HDACi (vorinostat, panobinostat, FK228, fimepinostat) (Dai et al. 2013; Li et al. 2019a; Qi et al. 2015; Xie et al. 2013; Zhao et al. 2017; Zhou et al. 2015). As FLT3-ITD drives the cell cycle as oncogene in MV4-11 cells, its inhibition consequently stalls cells in G1 phase and this can decrease DNA repair proteins (Bagrintseva et al. 2005; Kurosu et al. 2013). However, since AC220 and FK228 cause different types of cell cycle arrest, their suppressive effects on CHK1, WEE1, RAD51, and TS are unlikely due to altered cell cycle progression. Moreover, the combined applications of the drugs decrease therese proteins more strongly than the single drugs and this is not associated with a more pronounced arrest in one cell cycle phase.

This genetic depletion of WEE1, CHK1, and RAD51 as well as pharmacological drugs that target CHK1 (MK-1775, MK-8776, AZD1775) sensitize leukemic cells to apoptosis induction by HDACi. This is linked to a loss of cell cycle control and genomic intactness (Dai et al. 2013; Li et al. 2019a; Qi et al. 2015; Xie et al. 2013; Zhao et al. 2017; Zhou et al. 2015). It should be considered that the reduction of CHK1 does not necessarily stand for its inactivation as we see an activation of CHK1 (verified by its phosphorylation at S345). This was similarly observed in FLT3-ITD positive and negative leukemic cells that were treated with vorinostat (Zhou et al. 2015). Since the genetic depletion of CHK1 sensitizes cells to HDACi-induced apoptosis (Dai et al. 2013; Li et al. 2019a; Qi et al. 2015; Xie et al. 2013; Zhao et al. 2017; Zhou et al. 2015), we speculate that the activation of CHK1 by HDACi is a cellular survival response to the HDACi-induced replication stress and DNA damage. It also appears that HDACs can have a differential impact on DNA repair proteins in various leukemic cell models. In THP1 leukemic cells (AML cells from a one-year-old male child), FK228 reduced CHK1 and RAD51. This was also seen upon a genetic depletion of HDAC1/HDAC2 but not with RGFP966 (Zhao et al. 2017). Irrespective of such cell typespecific details and the need to fully characterize how class I HDACs share the workload to maintain DNA repair protein expression, the attenuation of WEE1, CHK1, RAD51, and TS are general and functionally important effects that these epigenetic drugs induce. The reduction of these proteins may serve as a pharmacodynamic marker to assess the efficacy of HDACi treatment in patients. Such markers are relevant because the general accumulation of acetylated histones does not necessarily inform about whether the HDACi will give beneficial effects in vivo (Müller and Krämer 2010; Wang et al. 2018).

Also coherent with previous reports (Dai et al. 2013; Li et al. 2019a; Qi et al. 2015; Xie et al. 2013; Zhao et al. 2017; Zhou et al. 2015), we found that the HDACi-induced loss of CHK1, WEE1, p21, and RAD51 was associated with cell cycle dysregulation and an accumulation of DNA strand breaks in AML cells with FLT3-ITD. This is linked to apoptosis which is a typical consequence of the loss of cell cycle control, DNA integrity, and tumorigenic signaling (Lee et al. 2017; Yue et al. 2020).

Taken together, we reveal that inhibitors of class I HDACs and of mutant FLT3 combine favorably against AML cells. This beneficial effect is associated with DNA damage and a loss of FLT3-ITD signaling.

Supplementary Information The online version contains supplementary material available at https://doi.org/10.1007/s00204-021-03174-1. 
Acknowledgements We thank for funding for this work. It was made possible by the German Research Foundation/Deutsche Forschungsgemeinschaft (KR 2291/8-1), the Brigitte und Dr. Konstanze WegenerStiftung (Projekt \#65), and intramural funding from the University Medical Center Mainz. Work in the Krämer group is additionally funded by the DFG - Project-ID 393547839 - SFB 1361, \#KR2291-91/12-1, and by the Wilhelm-Sander Foundation (Grant Nr. 2019.086.1).

Author contributions Conceived of or designed study: SJH, OHK. Performed research: VW, AMM, YZ, SJH, MB, APS, TB, TN, MD. Contributed new methods or models: WB, PSH, AS, SM, TK. Wrote the paper: OHK

Funding Open Access funding enabled and organized by Projekt DEAL. This work was funded by the German Research Foundation/ Deutsche Forschungsgemeinschaft (KR 2291/8-1), the Brigitte und Dr. Konstanze Wegener-Stiftung (Projekt \#65), and intramural funding from the University Medical Center Mainz. Work in the Krämer group is additionally funded by the DFG-Project-ID 393547839SFB 1361, \#KR2291-9-1/12-1, and by the Wilhelm-Sander Foundation (Grant Nr. 2019.086.1).

Availability of data and materials Uncropped images of immunoblot analyses are provided as Supplementary Information. Further data supporting the findings of this study are available from the corresponding author on scientific request.

Code availability Not applicable.

\section{Declarations}

Conflict of interest OHK AS, SM, TK, MB declare the patent "Synthesis, pharmacology and use of new and selective FMS-like tyrosine kinase 3 (FLT3) inhibitors, WO2019/034538". OHK, AS, SM declares the patent "Novel HDAC6 inhibitors and their uses, WO2016020369A1". These patents cover substances that were used to collect data that are shown in this article.

Open Access This article is licensed under a Creative Commons Attribution 4.0 International License, which permits use, sharing, adaptation, distribution and reproduction in any medium or format, as long as you give appropriate credit to the original author(s) and the source, provide a link to the Creative Commons licence, and indicate if changes were made. The images or other third party material in this article are included in the article's Creative Commons licence, unless indicated otherwise in a credit line to the material. If material is not included in the article's Creative Commons licence and your intended use is not permitted by statutory regulation or exceeds the permitted use, you will need to obtain permission directly from the copyright holder. To view a copy of this licence, visit http://creativecommons.org/licenses/by/4.0/.

\section{References}

Abe M, Pelus LM, Singh P et al (2016) Internal tandem duplication in FLT3 attenuates proliferation and regulates resistance to the FLT3 inhibitor AC220 by modulating p21Cdkn1a and Pbx1 in hematopoietic cells. PLoS ONE 11(7):e0158290. https://doi.org/ 10.1371/journal.pone. 0158290

Anantha RW, Vassin VM, Borowiec JA (2007) Sequential and synergistic modification of human RPA stimulates chromosomal DNA repair. J Biol Chem 282(49):35910-35923. https://doi.org/10. 1074/jbc.M704645200
Antar AI, Otrock ZK, Jabbour E, Mohty M, Bazarbachi A (2020) FLT3 inhibitors in acute myeloid leukemia: ten frequently asked questions. Leukemia 34(3):682-696. https://doi.org/10.1038/ s41375-019-0694-3

Bagrintseva K, Geisenhof S, Kern R et al (2005) FLT3-ITD-TKD dual mutants associated with AML confer resistance to FLT3 PTK inhibitors and cytotoxic agents by overexpression of Bcl-x(L). Blood 105(9):3679-3685. https://doi.org/10.1182/ blood-2004-06-2459

Bali P, George P, Cohen P et al (2004) Superior activity of the combination of histone deacetylase inhibitor LAQ824 and the FLT-3 kinase inhibitor PKC412 against human acute myelogenous leukemia cells with mutant FLT-3. Clin Cancer Res 10(15):4991-4997. https://doi.org/10.1158/1078-0432.CCR-04-0210

Beckerman R, Donner AJ, Mattia M et al (2009) A role for Chk1 in blocking transcriptional elongation of p21 RNA during the S-phase checkpoint. Genes Dev 23(11):1364-1377. https://doi. org/10.1101/gad.1795709

Berte N, Piée-Staffa A, Piecha N et al (2016) Targeting homologous recombination by pharmacological inhibitors enhances the killing response of glioblastoma cells treated with alkylating drugs. Mol Cancer Ther 15(11):2665-2678. https://doi.org/10.1158/15357163.MCT-16-0176

Beyer M, Kiweler N, Mahboobi S, Krämer OH (2017) How to distinguish between the activity of HDAC1-3 and HDAC6 with western blot. Methods Mol Biol 1510:355-364. https://doi.org/10.1007/ 978-1-4939-6527-4_26

Beyer M, Romanski A, Mustafa AM et al (2019) HDAC3 activity is essential for human leukemic cell growth and the expression of beta-catenin, MYC, and WT1. Cancers (basel). https://doi.org/10. 3390/cancers 11101436

Blaheta RA, Cinatl J Jr (2002) Anti-tumor mechanisms of valproate: a novel role for an old drug. Med Res Rev 22(5):492-511. https:// doi.org/10.1002/med.10017

Boice A, Bouchier-Hayes L (2020) Targeting apoptotic caspases in cancer. Biochim Biophys Acta Mol Cell Res 1867(6):118688. https://doi.org/10.1016/j.bbamcr.2020.118688

Boudny M, Trbusek M (2020) ATR-CHK1 pathway as a therapeutic target for acute and chronic leukemias. Cancer Treat Rev 88:102026. https://doi.org/10.1016/j.ctrv.2020.102026

Bradner JE, Mak R, Tanguturi SK et al (2010) Chemical genetic strategy identifies histone deacetylase 1 (HDAC1) and HDAC2 as therapeutic targets in sickle cell disease. Proc Natl Acad Sci USA 107(28):12617-12622. https://doi.org/10.1073/pnas.1006774107

Buchwald M, Pietschmann K, Brand P et al (2013) SIAH ubiquitin ligases target the nonreceptor tyrosine kinase ACK1 for ubiquitinylation and proteasomal degradation. Oncogene. https://doi.org/ 10.1038/onc.2012.515

Dai Y, Chen S, Kmieciak M et al (2013) The novel Chk1 inhibitor MK-8776 sensitizes human leukemia cells to HDAC inhibitors by targeting the intra-S checkpoint and DNA replication and repair. Mol Cancer Ther 12(6):878-889. https://doi.org/10.1158/15357163.MCT-12-0902

Dasgupta T, Antony J, Braithwaite AW, Horsfield JA (2016) HDAC8 inhibition blocks SMC3 deacetylation and delays cell cycle progression without affecting cohesin-dependent transcription in MCF7 cancer cells. J Biol Chem 291(24):12761-12770. https:// doi.org/10.1074/jbc.M115.704627

Deardorff MA, Bando M, Nakato R et al (2012) HDAC8 mutations in Cornelia de Lange syndrome affect the cohesin acetylation cycle. Nature 489(7415):313-317. https://doi.org/10.1038/nature11316

Demir S, Boldrin E, Sun Q et al (2020) Therapeutic targeting of mutant p53 in pediatric acute lymphoblastic leukemia. Haematologica 105(1):170-181. https://doi.org/10.3324/haematol.2018.199364

Elbaek CR, Petrosius V, Sorensen CS (2020) WEE1 kinase limits CDK activities to safeguard DNA replication and mitotic entry. 
Mutat Res 819-820:111694. https://doi.org/10.1016/j.mrfmmm. 2020.111694

Ghelli Luserna di Rora A, Cerchione C, Martinelli G, Simonetti G (2020) A WEE1 family business: regulation of mitosis, cancer progression, and therapeutic target. J Hematol Oncol 13(1):126. https://doi.org/10.1186/s13045-020-00959-2

Göder A, Emmerich C, Nikolova T et al (2018) HDAC1 and HDAC2 integrate checkpoint kinase phosphorylation and cell fate through the phosphatase-2A subunit PR130. Nat Commun 9(1):764. https://doi.org/10.1038/s41467-018-03096-0

Grundy MK, Buckanovich RJ, Bernstein KA (2020) Regulation and pharmacological targeting of RAD51 in cancer. NAR Cancer 2(3):zcaa024. https://doi.org/10.1093/narcan/zcaa024

Heidel F, Solem FK, Breitenbuecher F et al (2006) Clinical resistance to the kinase inhibitor PKC412 in acute myeloid leukemia by mutation of Asn-676 in the FLT3 tyrosine kinase domain. Blood 107(1):293-300. https://doi.org/10.1182/blood-2005-06-2469

Kale J, Osterlund EJ, Andrews DW (2018) BCL-2 family proteins: changing partners in the dance towards death. Cell Death Differ 25(1):65-80. https://doi.org/10.1038/cdd.2017.186

Kanno S, Maeda N, Tomizawa A, Yomogida S, Katoh T, Ishikawa M (2012) Characterization of cells resistant to the potent histone deacetylase inhibitor spiruchostatin B (SP-B) and effect of overexpressed $\mathrm{p} 21 \mathrm{waf} 1 / \mathrm{cip} 1$ on the SP-B resistance or susceptibility of human leukemia cells. Int J Oncol 41(3):862-868. https://doi. org/10.3892/ijo.2012.1507

Kiweler N, Brill B, Wirth M et al (2018) The histone deacetylases HDAC1 and HDAC2 are required for the growth and survival of renal carcinoma cells. Arch Toxicol 92(7):2227-2243. https:// doi.org/10.1007/s00204-018-2229-5

Kiweler N, Wünsch D, Wirth M et al (2020) Histone deacetylase inhibitors dysregulate DNA repair proteins and antagonize metastasis-associated processes. J Cancer Res Clin Oncol 146(2):343-356. https://doi.org/10.1007/s00432-019-03118-4

Kopp B, Khoury L, Audebert M (2019) Validation of the gammaH2AX biomarker for genotoxicity assessment: a review. Arch Toxicol. https://doi.org/10.1007/s00204-019-02511-9

Kosan C, Ginter T, Heinzel T, Krämer OH (2013) STAT5 acetylation: mechanisms and consequences for immunological control and leukemogenesis. JAKSTAT 2(4):e26102. https://doi.org/10. $4161 / \mathrm{jkst} .26102$

Krämer OH (2009) HDAC2: a critical factor in health and disease. Trends Pharmacol Sci 30(12):647-655. https://doi.org/10. 1016/j.tips.2009.09.007

Krämer OH, Knauer SK, Zimmermann D, Stauber RH, Heinzel T (2008) Histone deacetylase inhibitors and hydroxyurea modulate the cell cycle and cooperatively induce apoptosis. Oncogene 27(6):732-740. https://doi.org/10.1038/sj.onc.1210677

Krämer OH, Mahboobi S, Sellmer A (2014) Drugging the HDAC6HSP90 interplay in malignant cells. Trends Pharmacol Sci 35(10):501-509. https://doi.org/10.1016/j.tips.2014.08.001

Krumm A, Barckhausen C, Kucuk P et al (2016) Enhanced histone deacetylase activity in malignant melanoma provokes RAD51 and FANCD2-triggered drug resistance. Can Res 76(10):30673077. https://doi.org/10.1158/0008-5472.CAN-15-2680

Kurosu T, Nagao T, Wu N, Oshikawa G, Miura O (2013) Inhibition of the PI3K/Akt/GSK3 pathway downstream of BCR/ ABL, Jak2-V617F, or FLT3-ITD downregulates DNA damageinduced Chk1 activation as well as $\mathrm{G} 2 / \mathrm{M}$ arrest and prominently enhances induction of apoptosis. PLoS ONE 8(11):e79478. https://doi.org/10.1371/journal.pone.0079478

Lakshmaiah KC, Jacob LA, Aparna S, Lokanatha D, Saldanha SC (2014) Epigenetic therapy of cancer with histone deacetylase inhibitors. J Cancer Res Ther 10(3):469-478. https://doi.org/10. 4103/0973-1482.137937
Lee LY, Hernandez D, Rajkhowa T et al (2017) Preclinical studies of gilteritinib, a next-generation FLT3 inhibitor. Blood 129(2):257260. https://doi.org/10.1182/blood-2016-10-745133

Li YZ, Yu S, Yan PA et al (2017) Crotonoside exhibits selective post-inhibition effect in AML cells via inhibition of FLT3 and HDAC3/6. Oncotarget 8(61):103087-103099. https://doi.org/10. 18632/oncotarget.20710

Li X, Su Y, Madlambayan G et al (2019a) Antileukemic activity and mechanism of action of the novel PI3K and histone deacetylase dual inhibitor CUDC-907 in acute myeloid leukemia. Haematologica 104(11):2225-2240. https://doi.org/10.3324/haematol. 2018.201343

Li Y, Wang F, Chen X et al (2019b) Zinc-dependent deacetylase (HDAC) inhibitors with different zinc binding groups. Curr Top Med Chem 19(3):223-241. https://doi.org/10.2174/1568026619 666190122144949

Li G, Tian Y, Zhu WG (2020) The roles of histone deacetylases and their inhibitors in cancer therapy. Front Cell Dev Biol 8:576946. https://doi.org/10.3389/fcell.2020.576946

Luo Y, Li H (2020) Structure-based inhibitor discovery of class I histone deacetylases (HDACs). Int J Mol Sci. https://doi.org/10.3390/ ijms 21228828

Mahboobi S, Sellmer A, Pongratz H et al (2019) Synthesis, pharmacology and use of new and selective FMS-like tyrosine kinase 3 (FLT3) inhibitors. https://patentscope.wipo.int/search/en/detail. jsf?docId=WO2019034538. WO2019/034538

Majothi S, Adams D, Loke J, Stevens SP, Wheatley K, Wilson JS (2020) FLT3 inhibitors in acute myeloid leukaemia: assessment of clinical effectiveness, adverse events and future research-a systematic review and meta-analysis. Syst Rev 9(1):285. https://doi. org/10.1186/s13643-020-01540-1

Marensi V, Keeshan KR, MacEwan DJ (2021) Pharmacological impact of FLT3 mutations on receptor activity and responsiveness to tyrosine kinase inhibitors. Biochem Pharmacol 183:114348. https://doi.org/10.1016/j.bcp.2020.114348

Marx C, Sonnemann J, Beyer M et al (2021) Mechanistic insights into p53-regulated cytotoxicity of combined entinostat and irinotecan against colorectal cancer cells. Mol Oncol. https://doi.org/10. 1002/1878-0261.13060

Marx-Blümel L, Marx C, Kühne M, Sonnemann J (2017) Assessment of HDACi-induced cytotoxicity. Methods Mol Biol 1510:23-45. https://doi.org/10.1007/978-1-4939-6527-4_3

Matthews GM, Mehdipour P, Cluse LA et al (2015) Functional-genetic dissection of HDAC dependencies in mouse lymphoid and myeloid malignancies. Blood 126(21):2392-2403. https://doi.org/10. 1182/blood-2015-03-632984

Müller S, Krämer OH (2010) Inhibitors of HDACs-effective drugs against cancer? Curr Cancer Drug Targets 10(2):210-228

Nikolova T, Kiweler N, Krämer OH (2017) Interstrand crosslink repair as a target for HDAC inhibition. Trends Pharmacol Sci 38(9):822836. https://doi.org/10.1016/j.tips.2017.05.009

Nishioka C, Ikezoe T, Yang J, Takeuchi S, Koeffler HP, Yokoyama A (2008) MS-275, a novel histone deacetylase inhibitor with selectivity against HDAC1, induces degradation of FLT3 via inhibition of chaperone function of heat shock protein 90 in AML cells. Leuk Res 32(9):1382-1392. https://doi.org/10.1016/j.leukres. 2008.02.018

Noack K, Mahendrarajah N, Hennig D et al (2017) Analysis of the interplay between all-trans retinoic acid and histone deacetylase inhibitors in leukemic cells. Arch Toxicol 91(5):2191-2208. https://doi.org/10.1007/s00204-016-1878-5

Perl AE (2019) Availability of FLT3 inhibitors: how do we use them? Blood 134(9):741-745. https://doi.org/10.1182/blood.20198 76821

Pietschmann K, Bolck HA, Buchwald M et al (2012) Breakdown of the FLT3-ITD/STAT5 axis and synergistic apoptosis induction by 
the histone deacetylase inhibitor panobinostat and FLT3-specific inhibitors. Mol Cancer Ther 11(11):2373-2383. https://doi.org/ 10.1158/1535-7163.MCT-12-0129

Pojani E, Barlocco D (2020) Romidepsin (FK228), an histone deacetylase inhibitor, and its analogues in cancer chemotherapy. Curr Med Chem. https://doi.org/10.2174/09298673276662002031 13926

Pons M, Reichardt CM, Hennig D et al (2018) Loss of Wilms tumor 1 protein is a marker for apoptosis in response to replicative stress in leukemic cells. Arch Toxicol 92(6):2119-2135. https://doi.org/ 10.1007/s00204-018-2202-3

Pons M, Zeyn Y, Zahn S et al (2021) Oncogenic kinase cascades induce molecular mechanisms that protect leukemic cell models from lethal effects of de novo dNTP synthesis inhibition. Cancers (basel). https://doi.org/10.3390/cancers13143464

Pulte ED, Norsworthy KJ, Wang Y et al (2021) FDA approval summary: gilteritinib for relapsed or refractory acute myeloid leukemia with a FLT3 mutation. Clin Cancer Res. https://doi.org/10. 1158/1078-0432.CCR-20-4271

Qi W, Zhang W, Edwards H et al (2015) Synergistic anti-leukemic interactions between panobinostat and MK-1775 in acute myeloid leukemia ex vivo. Cancer Biol Ther 16(12):1784-1793. https:// doi.org/10.1080/15384047.2015.1095406

Rogakou EP, Nieves-Neira W, Boon C, Pommier Y, Bonner WM (2000) Initiation of DNA fragmentation during apoptosis induces phosphorylation of $\mathrm{H} 2 \mathrm{AX}$ histone at serine 139. J Biol Chem 275(13):9390-9395. https://doi.org/10.1074/jbc.275.13.9390

Rosato RR, Almenara JA, Grant S (2003) The histone deacetylase inhibitor MS-275 promotes differentiation or apoptosis in human leukemia cells through a process regulated by generation of reactive oxygen species and induction of p21CIP1/WAF1 1. Can Res 63(13):3637-3645

Rosato RR, Almenara JA, Yu C, Grant S (2004) Evidence of a functional role for $\mathrm{p} 21 \mathrm{WAF} 1 / \mathrm{CIP} 1$ down-regulation in synergistic antileukemic interactions between the histone deacetylase inhibitor sodium butyrate and flavopiridol. Mol Pharmacol 65(3):571581. https://doi.org/10.1124/mol.65.3.571

Sasakawa Y, Naoe Y, Inoue T et al (2002) Effects of FK228, a novel histone deacetylase inhibitor, on human lymphoma U-937 cells in vitro and in vivo. Biochem Pharmacol 64(7):1079-1090. https://doi.org/10.1016/s0006-2952(02)01261-3

Scholl S, Fleischmann M, Schnetzke U, Heidel FH (2020) Molecular mechanisms of resistance to FLT3 inhibitors in acute myeloid leukemia: ongoing challenges and future treatments. Cells. https:// doi.org/10.3390/cells9112493

Seedhouse CH, Hunter HM, Lloyd-Lewis B et al (2006) DNA repair contributes to the drug-resistant phenotype of primary acute myeloid leukaemia cells with FLT3 internal tandem duplications and is reversed by the FLT3 inhibitor PKC412. Leukemia 20(12):2130-2136. https://doi.org/10.1038/sj.leu.2404439

Sellmer A, Stangl H, Beyer M et al (2018) Marbostat-100 defines a new class of potent and selective antiinflammatory and antirheumatic histone deacetylase 6 inhibitors. J Med Chem 61(8):3454-3477. https://doi.org/10.1021/acs.jmedchem.7b01593
Sellmer A, Pilsl B, Beyer M et al (2020) A series of novel aryl-methanone derivatives as inhibitors of FMS-like tyrosine kinase 3 (FLT3) in FLT3-ITD-positive acute myeloid leukemia. Eur J Med Chem 193:112232. https://doi.org/10.1016/j.ejmech.2020.112232

Smith CC, Wang Q, Chin CS et al (2012) Validation of ITD mutations in FLT3 as a therapeutic target in human acute myeloid leukaemia. Nature 485(7397):260-263. https://doi.org/10.1038/nature11016

Thompson T, Danilenko M, Vassilev L, Studzinski GP (2010) Tumor suppressor p53 status does not determine the differentiationassociated G(1) cell cycle arrest induced in leukemia cells by 1,25-dihydroxyvitamin $\mathrm{D}(3)$ and antioxidants. Cancer Biol Ther 10(4):344-350. https://doi.org/10.4161/cbt.10.4.12366

Wang H, Zhou W, Zheng Z et al (2012) The HDAC inhibitor depsipeptide transactivates the p53/p21 pathway by inducing DNA damage. DNA Repair (AMst) 11(2):146-156. https://doi.org/10. 1016/j.dnarep.2011.10.014

Wang L, Beier UH, Akimova T et al (2018) Histone/protein deacetylase inhibitor therapy for enhancement of Foxp3+ T-regulatory cell function posttransplantation. Am J Transplant 18(7):1596-1603. https://doi.org/10.1111/ajt.14749

Xie C, Drenberg C, Edwards H et al (2013) Panobinostat enhances cytarabine and daunorubicin sensitivities in AML cells through suppressing the expression of BRCA1, CHK1, and Rad51. PLoS ONE 8(11):e79106. https://doi.org/10.1371/journal.pone.0079106

Yan B, Chen Q, Xu J, Li W, Xu B, Qiu Y (2020) Low-frequency TP53 hotspot mutation contributes to chemoresistance through clonal expansion in acute myeloid leukemia. Leukemia 34(7):18161827. https://doi.org/10.1038/s41375-020-0710-7

Yuan LL, Green A, David L et al (2014) Targeting CHK1 inhibits cell proliferation in FLT3-ITD positive acute myeloid leukemia. Leuk Res 38(11):1342-1349. https://doi.org/10.1016/j.leukres. 2014.08.020

Yue J, Vendramin R, Liu F et al (2020) Targeted chemotherapy overcomes drug resistance in melanoma. Genes Dev 34(9-10):637649. https://doi.org/10.1101/gad.333864.119

Zarrinkar PP, Gunawardane RN, Cramer MD et al (2009) AC220 is a uniquely potent and selective inhibitor of FLT3 for the treatment of acute myeloid leukemia (AML). Blood 114(14):2984-2992. https://doi.org/10.1182/blood-2009-05-222034

Zhao J, Xie C, Edwards H, Wang G, Taub JW, Ge Y (2017) Histone deacetylases 1 and 2 cooperate in regulating BRCA1, CHK1, and RAD51 expression in acute myeloid leukemia cells. Oncotarget 8(4):6319-6329. https://doi.org/10.18632/oncotarget.14062

Zhou L, Zhang Y, Chen S et al (2015) A regimen combining the Wee1 inhibitor AZD1775 with HDAC inhibitors targets human acute myeloid leukemia cells harboring various genetic mutations. Leukemia 29(4):807-818. https://doi.org/10.1038/leu.2014.296

Publisher's Note Springer Nature remains neutral with regard to jurisdictional claims in published maps and institutional affiliations. 


\section{Authors and Affiliations}

\section{Vanessa Wachholz ${ }^{1}$ Al-Hassan M. Mustafa ${ }^{1,2}$ (1) $\cdot$ Yanira Zeyn ${ }^{1}$. Sven J. Henninger ${ }^{1}$ Mandy Beyer ${ }^{1}$. Melanie Dzulko ${ }^{1}$. Andrea Piée-Staffa ${ }^{1}$. Christina Brachetti ${ }^{1}$. Patricia S. Haehnel ${ }^{3,4}$. Andreas Sellmer ${ }^{5}$. Siavosh Mahboobi ${ }^{5} \cdot$ Thomas Kindler $^{3,4}$. Walburgis Brenner ${ }^{6}$ (D) . Teodora Nikolova ${ }^{1}$. Oliver H. Krämer ${ }^{1} \mathbb{C}$}

Vanessa Wachholz

vanessawachholz@web.de

Al-Hassan M. Mustafa

alabdeen@uni-mainz.de

Yanira Zeyn

yanira.zeyn@uni-mainz.de

Sven J. Henninger

svhennin@uni-mainz.de

Mandy Beyer

manbeyer@uni-mainz.de

Melanie Dzulko

medzulko@uni-mainz.de

Andrea Piée-Staffa

pieean01@uni-mainz.de

Christina Brachetti

brachett@uni-mainz.de

Patricia S. Haehnel

p.haehnel@uni-mainz.de

Andreas Sellmer

Andreas.Sellmer@chemie.uni-regensburg.de

Siavosh Mahboobi

Siavosh.Mahboobi@chemie.uni-regensburg.de
Thomas Kindler

kindlet@uni-mainz.de

Walburgis Brenner

brenner@uni-mainz.de

Teodora Nikolova

nikolova@uni-mainz.de

1 Department of Toxicology, University Medical Center, Johannes Gutenberg University Mainz, Mainz, Germany

2 Department of Zoology, Faculty of Science, Aswan University, Aswan, Egypt

3 Department of Hematology, Medical Oncology and Pneumology, University Medical Center of the Johannes Gutenberg-University, Mainz, Germany

4 German Consortia for Translational Cancer Research, Mainz, Germany

5 Faculty of Chemistry and Pharmacy, Institute of Pharmacy, University of Regensburg, 93040 Regensburg, Germany

6 Clinic for Obstetrics and Women's Health, Johannes Gutenberg University Mainz, Mainz, Germany 